\title{
Global simulations of aerosol processing in clouds
}

\author{
C. Hoose ${ }^{1, *}$, U. Lohmann ${ }^{1}$, R. Bennartz ${ }^{2}$, B. Croft ${ }^{3}$, and G. Lesins ${ }^{3}$ \\ ${ }^{1}$ ETH Zurich, Institute for Atmospheric and Climate Science, Zurich, Switzerland \\ ${ }^{2}$ Atmospheric and Oceanic Sciences, University of Wisconsin, Madison, WI, USA \\ ${ }^{3}$ Department of Physics and Atmospheric Science, Dalhousie University, Halifax, Canada \\ *now at: Department of Geosciences, University of Oslo, Norway
}

Received: 17 June 2008 - Published in Atmos. Chem. Phys. Discuss.: 15 July 2008

Revised: 7 October 2008 - Accepted: 7 October 2008 - Published: 2 December 2008

\begin{abstract}
An explicit and detailed representation of indroplet and in-crystal aerosol particles in stratiform clouds has been introduced in the global aerosol-climate model ECHAM5-HAM. The new scheme allows an evaluation of the cloud cycling of aerosols and an estimation of the relative contributions of nucleation and collision scavenging, as opposed to evaporation of hydrometeors in the global aerosol processing by clouds. On average an aerosol particle is cycled through stratiform clouds 0.5 times. The new scheme leads to important changes in the simulated fraction of aerosol scavenged in clouds, and consequently in the aerosol wet deposition. In general, less aerosol is scavenged into clouds with the new prognostic treatment than what is prescribed in standard ECHAM5-HAM. Aerosol concentrations, size distributions, scavenged fractions and cloud droplet concentrations are evaluated and compared to different observations. While the scavenged fraction and the aerosol number concentrations in the marine boundary layer are well represented in the new model, aerosol optical thickness, cloud droplet number concentrations in the marine boundary layer and the aerosol volume in the accumulation and coarse modes over the oceans are overestimated. Sensitivity studies suggest that a better representation of belowcloud scavenging, higher in-cloud collision coefficients, or a reduced water uptake by seasalt aerosols could reduce these biases.
\end{abstract}

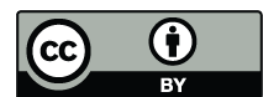

Correspondence to: C. Hoose (corinna.hoose@geo.uio.no)

\section{Introduction}

Pruppacher and Jaenicke (1995) estimated that, globally averaged, an atmospheric aerosol particle, sampled at a distance from a specific source, has been cycled three times through a cloud. This includes cycling through both stratiform and convective clouds. Uptake into cloud droplets, collision-coalescence, chemical processing inside hydrometeors and release back into the atmosphere has important implications for the physical and chemical properties of the aerosol.

In detail, a cycle of an aerosol particle through a liquid cloud can involve the following processes (Fig. 1): the bigger and hygroscopic aerosol particles act preferably as the cloud condensation nuclei on which cloud droplets form. Cloud droplets can collect more aerosol particles and other cloud droplets by collisions. The soluble part of the aerosol particles (e.g. sulfate, salts) dissolves in the cloud water. Additionally, atmospheric gases can transfer into droplets and undergo chemical reactions in the aqueous phase. E.g., the majority of the atmospheric sulfate mass is formed by reactions inside cloud droplets (Barth et al., 2000). If precipitation is formed, all material collected in the precipitating droplets is removed from the atmosphere (wet deposition). However, a large fraction of clouds does not form precipitation, but evaporates (Lin and Rossow, 1996), and furthermore a large fraction of precipitation evaporates before it reaches the ground. In this case, the dissolved material concentrates in the liquid phase or crystallizes, and together with any insoluble material inside the droplet, forms one new, internally mixed aerosol particle (Pruppacher and Klett, 1997). These reemitted particles are larger than prior to cloud processing.

Effects of cloud processing on the aerosol size distribution have been observed by Hoppel et al. $(1986,1990)$. Marine boundary layer aerosol size distributions were found to

Published by Copernicus Publications on behalf of the European Geosciences Union. 


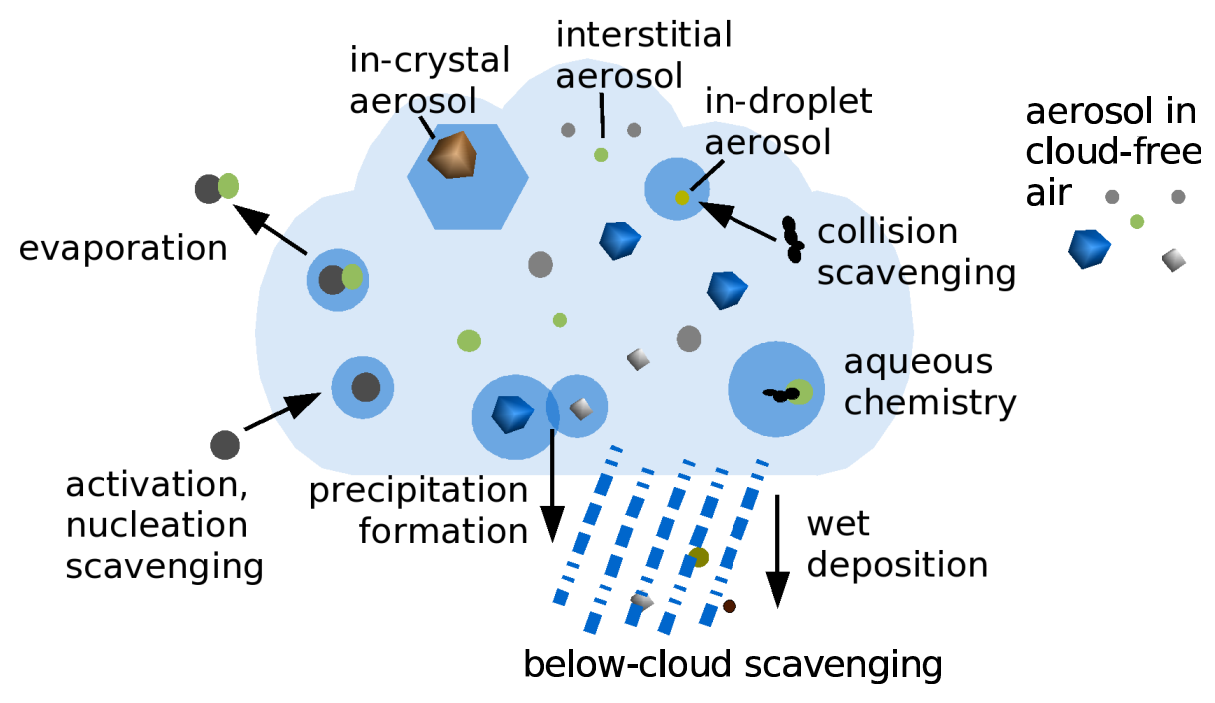

Fig. 1. Illustration of the processes involved in the aerosol processing in clouds, and of interstitial, in-droplet and in-crystal aerosol (on the basis of a figure by Ghan and Schwartz, 2007).

exhibit a distinct bimodal shape. The second (larger) peak is attributed to activated particles which have grown through cloud processing, while freshly nucleated, not activated particles constitute the smaller mode. Bower et al. (1997) observed significant modifications of the aerosol size distribution and hygroscopic properties after the passage through a hill cap cloud. Addition of sulfate mass often increased the number of cloud condensation nuclei available for subsequent cloud formation.

Most global aerosol models do not treat the in-cloud aerosol explicitly, but account for the effects of clouds on the aerosol size distribution in simplified ways. For example, sulfate that is formed in the aqueous phase, can for example be added to the accumulation and coarse mode particles (Stier et al., 2005; Roelofs et al., 2006). The pH-dependent aqueous phase chemistry in droplets of different sizes is approximated by Roelofs et al. (2006) by the use of two bins for concentrated and diluted droplets. Tost et al. (2007) explicitly compute the $\mathrm{pH}$-values of clouds and precipitation with the help of a prescribed precipitation size distribution and size-dependent transfer coefficients for atmospheric gases.

Only a few global models include an explicit representation and separate tracers for cloudborne particles: the Hadley Center climate model (HADAM4), the Goddard Institute for Space Studies (GISS) ModelE and the Model for Integrated Research on Atmospheric Global Exchanges (MIRAGE) modeling system. HADAM4 (Jones et al., 2001) calculates sulfate mass for three modes, one of which represents sulfate dissolved in cloud droplets. In GISS ModelE (Koch et al., 2006), a stratiform dissolved species budget is calculated for all soluble and partially soluble aerosol and gasphase species, saving the dissolved fraction for the duration of the cloud lifetime. As GISS ModelE simulates only the mass and not the number of aerosols, the influence of cloud processing on aerosol size is not treated. MIRAGE (Easter et al., 2004) explicitly predicts mass and number of cloudborne particles in four different lognormal modes and for six different chemical components. In HADAM4 and MIRAGE, transfer into these modes is possible via activation and, for Aitken mode particles only, Brownian diffusion.

Recently, the global aerosol-climate model ECHAM5HAM (Stier et al., 2005) has been extended by an explicit treatment of in-cloud aerosol particles (Hoose et al., 2008). Differently from HADAM4, GISS ModelE and MIRAGE, in-droplet and in-crystal particles are treated separately. Uptake of aerosols into droplets and crystals by nucleation scavenging and by collisions between all interstitial particles and hydrometeors, and release of aerosols during droplet evaporation, especially during the Wegener-Bergeron-Findeisen process in mixed-phase clouds, are simulated. The model performance has been evaluated in single-column simulations for three different mixed-phase cloud cases at the high altitude alpine research station Jungfraujoch (Switzerland). The uptake, transfer and release processes between interstitial and in-cloud aerosol were qualitatively well captured (Hoose et al., 2008).

In this paper we apply the extended aerosol-climate model, as introduced by Hoose et al. (2008), to global simulations of aerosol processing in stratiform clouds.

\section{Model description}

ECHAM5-HAM (Stier et al., 2005) is a global aerosolclimate model with a prognostic treatment of cloud droplets and ice crystals in stratiform clouds (Lohmann et al., 2007). 
Table 1. Scavenging coefficients $R_{j}$ for stratiform clouds, applied to both mass and number, of the seven modes in standard ECHAM5-HAM (simulation CTL). Adapted from Stier et al. (2005). The abbreviation of the modes are: NS=nucleation soluble, $\mathrm{KS}=$ Aitken soluble, $\mathrm{AS}=$ accumulation soluble, $\mathrm{CS}=$ coarse soluble, $\mathrm{KI}=$ Aitken insoluble, $\mathrm{AI}=$ accumulation insoluble, $\mathrm{CI}=$ coarse insoluble.

\begin{tabular}{lccccccc}
\hline & $R_{\mathrm{NS}}$ & $R_{\mathrm{KS}}$ & $R_{\mathrm{AS}}$ & $R_{\mathrm{CS}}$ & $R_{\mathrm{KI}}$ & $R_{\mathrm{AI}}$ & $R_{\mathrm{CI}}$ \\
\hline $0^{\circ} \mathrm{C}<T$ & 0.10 & 0.25 & 0.85 & 0.99 & 0.20 & 0.40 & 0.40 \\
$-35<T<0^{\circ} \mathrm{C}$ & 0.10 & 0.40 & 0.75 & 0.75 & 0.10 & 0.40 & 0.40 \\
$T<-35^{\circ} \mathrm{C}$ & 0.10 & 0.10 & 0.10 & 0.10 & 0.10 & 0.10 & 0.10 \\
\hline
\end{tabular}

Both the cloud droplet activation and the ice crystal formation through homogeneous and heterogeneous freezing depend on the simulated aerosol number concentration, size distribution and composition.

The aerosol module HAM represents the atmospheric aerosol in seven internally and externally mixed modes, consisting of the five components sulfate, black carbon, organic carbon, sea salt and mineral dust. Hoose et al. (2008) have extended HAM by two additional modes, which include indroplet and in-crystal particles in stratiform clouds. The number concentrations of in-droplet and in-crystal aerosol particles are set equal to the number concentrations of droplets and crystals, assuming that particles inside hydrometeors or released from evaporating hydrometeors form aggregates. The seven modes of the standard model represent the total (interstitial plus in-cloud) aerosol. The partitioning between in-cloud and interstitial aerosols is calculated from prescribed scavenging ratios (as listed in Table 1, illustrated in Fig. 2a). In the extended model, the seven modes only represent the interstitial aerosol (scavenging ratio of $0 \%$ ), while the two new in-cloud modes are assumed to be $100 \%$ scavenged (Fig. 2b). The ratio of in-cloud aerosol to the total aerosol, either in terms of mass or number, which gives the average scavenging ratio, is entirely determined by the nucleation and collision scavenging processes during cloud formation and evolution, and by the release of aerosol particles back into the interstitial phase upon droplet evaporation or crystal sublimation. A detailed model description can be found in Hoose et al. (2008).

The aerosol processing is now simulated globally. In contrast to the single column model studies by Hoose et al. (2008), aerosol, cloud droplet and ice crystal vertical and horizontal transport, vertical diffusion and aerosol sedimentation are now included. Ice crystal sedimentation is neglected. Transport and diffusion of in-droplet and in-crystal aerosol mass and the corresponding droplet and crystal numbers can be inconsistent if different concentration gradients exist. This can lead to unrealistic sizes of the cloudborne particles. Cloudborne particles with an unphysical dry radius smaller than $5 \mathrm{~nm}$ or larger than $50 \mu \mathrm{m}$ are set to a standard size of $50 \mathrm{~nm}$, while conserving the aerosol mass such that the global aerosol mass budgets are closed.
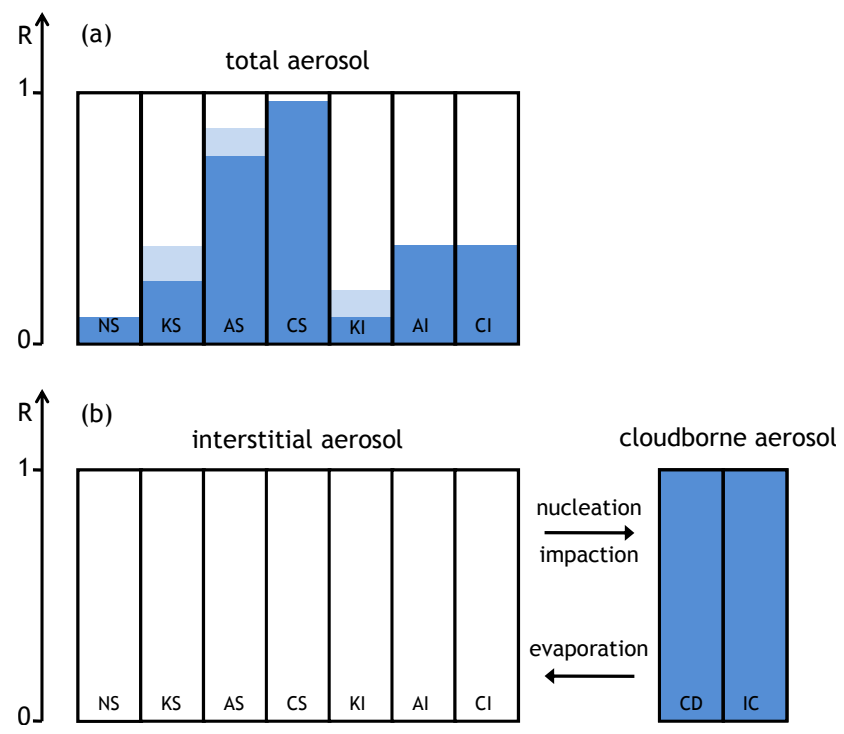

Fig. 2. Partitioning between interstitial and cloud-borne aerosol and scavenging ratios $\mathrm{R}$ for the seven plus two aerosol modes in the standard model (a) and with the new aerosol processing scheme (b). For the standard model (a), the light and dark blue indicates the values of $R$ in liquid and mixed-phase clouds (see Table 1). For ice clouds, $R$ is 0.1 for all modes. The abbreviations of the modes are listed in Table 1.

Cloud droplet evaporation and ice crystal sublimation is treated following a homogeneous mixing assumption. If cloud water partially evaporates, it is assumed that the hydrometeors shrink, but that their number is not reduced. Therefore also no aerosol is released in this case. An exception is the Wegener-Bergeron-Findeisen process, where complete evaporation of all liquid water and all droplets is assumed once a threshold ice water content is exceeded (Lohmann et al., 2007). Release of aerosol particles from evaporating hydrometeors also occurs if the cloud cover decreases. Below-cloud evaporation is treated in the following simplified way: The mass fluxes of precipitation and the incorporated aerosol of each species are computed, and in each below-cloud level the fraction of evaporating precipitation is calculated as a function of the relative humidity. The same fraction is applied to the release of aerosol mass from the evaporating hydrometeors, i.e. here an inhomogeneous mixing assumption is applied, in contrast to the evaporation of cloud droplets and ice crystals. This treatment is consistent with the parameterization in standard ECHAM5-HAM. The aerosol mass from the evaporating precipitation particles is attributed to the soluble/mixed coarse mode, because rain drops have formed by coagulation of a large number of cloud droplets and can be assumed to contain a significant mass of aerosol. As no rain drop number is computed in ECHAM5-HAM, the number of aerosol particles resulting from the evaporation of precipitation is estimated from the 
Table 2. Sensitivity simulations. $\gamma$ is the autoconversion tuning parameter. AP stands for aerosol processing.

\begin{tabular}{lll}
\hline Simulation & Description & $\gamma$ \\
\hline CTL & $\begin{array}{l}\text { Control simulation, similar to simulation ECHAM5-RH by Lohmann et al. (2007), but with a different } \\
\text { activation parameterization (Ghan et al., 1993) and a different autoconversion parameterization (Be- }\end{array}$ & 80 \\
& heng, 1994) & 400 \\
AP & as CTL, but with explicit representation of aerosol processing \\
AP-bcs & as AP, but with revised below-cloud scavenging after Croft et al. (2008a) & 400 \\
AP-aod & as AP, but with reduced water uptake on sea salt aerosols & 400 \\
AP-coll & as AP, but with higher collision coefficients for accumulation and coarse mode particles & 20 \\
AP-comb & AP-bcs, AP-aod and AP-coll combined & 20 \\
\hline
\end{tabular}

Table 3. Global mean liquid water path LWP, ice water path IWP, shortwave cloud forcing SCF, longwave cloud forcing LCF, net top-ofthe-atmosphere radiation $F_{\text {net }}$, grid-mean cloud droplet burden $N_{l}^{\mathrm{B}}$, the cloud droplet burden $N_{l \text {,cloudy }}^{\mathrm{B}}$ from cloudy areas only, precipitation $\mathrm{P}$ and aerosol optical depth AOD for the sensitivity simulations described in Table 2. Observational estimates are from O'Dell et al. (2008), Greenwald et al. (1993) and Weng et al. (1997) (LWP), Storelvmo et al. (2008) (IWP), Kiehl and Trenberth (1997) (SCF and LCF), Han et al. (1998) ( $\left.N_{l, \text { cloudy }}^{\mathrm{B}}\right)$, Adler et al. (2003) (P) and (Kinne, 2008) (AOD).

\begin{tabular}{|c|c|c|c|c|c|c|c|c|c|}
\hline Simulation & 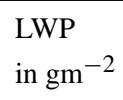 & $\begin{array}{l}\text { IWP } \\
\text { in } \mathrm{gm}^{-2}\end{array}$ & $\begin{array}{l}\text { SCF } \\
\text { in } \mathrm{Wm}^{-2}\end{array}$ & $\begin{array}{l}\text { LCF } \\
\text { in } \mathrm{Wm}^{-2}\end{array}$ & $\begin{array}{l}F_{\text {net }} \\
\text { in } \mathrm{Wm}^{-2}\end{array}$ & $\begin{array}{l}N_{l}^{\mathrm{B}} \\
\text { in } 10^{10} \mathrm{~m}^{-2}\end{array}$ & $\begin{array}{l}N_{l, \text { cloudy }}^{\mathrm{B}} \\
\text { in } 10^{10} \mathrm{~m}^{-2}\end{array}$ & $\begin{array}{l}\mathrm{P} \\
\text { in } \mathrm{mmd}^{-1}\end{array}$ & AOD \\
\hline Observations & $48-86^{\mathrm{a}}$ & 29 & -50 & 30 & $0^{\mathrm{b}}$ & & 4 & 2.74 & $0.15-0.19$ \\
\hline CTL & 62.5 & 19.1 & -55.8 & 31.6 & -0.52 & 4.7 & 7.6 & 2.85 & 0.18 \\
\hline AP & 44.1 & 19.3 & -51.1 & 31.2 & -0.85 & 4.2 & 9.5 & 2.86 & 0.42 \\
\hline AP-bcs & 42.6 & 19.2 & -51.3 & 31.2 & +0.22 & 3.8 & 9.6 & 2.87 & 0.34 \\
\hline AP-aod & 45.4 & 19.3 & -52.2 & 31.2 & -0.37 & 4.4 & 9.8 & 2.87 & 0.32 \\
\hline AP-coll & 62.2 & 19.2 & -53.8 & 31.6 & -0.69 & 3.0 & 7.3 & 2.86 & 0.30 \\
\hline AP-comb & 62.7 & 19.2 & -54.4 & 31.6 & -0.22 & 3.1 & 7.6 & 2.85 & 0.22 \\
\hline
\end{tabular}

a The satellite retrievals are restricted to oceans.

$\mathrm{b}$ The radiation budget at the top of the atmosphere has to be balanced, otherwise the climate would rapidly drift to a warmer/colder state.

evaporating precipitation mass with the assumption of a radius of $100 \mu \mathrm{m}$ per rain drop. With an assumed rain drop radius of $50 \mu \mathrm{m}$ instead of $100 \mu \mathrm{m}$, the global number burden of the soluble/mixed coarse mode is increased by $40.8 \%$; the global mean aerosol optical depth is increased by $4.87 \%$, and the global mean cloud droplet burden is increased by $1.05 \%$. The effects on the LWP and the radiative fluxes are minor. The mean radius of evaporating rain droplets is a very uncertain parameter and is likely to vary strongly both spatially and temporally. This uncertainty could be reduced with a prognostic treatment of rain, from which the mean diameter can actually be calculated. In the standard model version without explicit aerosol processing, particles are released back into the mode from which they were previously scavenged, i.e. their composition and size distribution remains unchanged.

Table 2 lists the simulations which are compared and discussed in this article. Simulation CTL is similar to the reference simulation described by Lohmann et al. (2007), with minor updates and corrections (Lohmann, 2008). Different autoconversion and activation parameterizations are applied in this study, as described below. For autoconversion, the process of transformation of cloud droplets to rain droplets, a different parameterization is used in this study. Lohmann et al. (2007) used Khairoutdinov and Kogan's (2000) scheme, which has the following form:

$$
\begin{aligned}
& \left.\frac{d q_{l}}{d t}\right|_{\text {aut }}=-\gamma 10^{3} \rho_{\text {air }} \times 1350\left(\frac{q_{l}}{10^{3} \rho_{\text {air }}}\right)^{2.47} N_{l}^{-1.79} \\
& \left.\frac{d N_{l}}{d t}\right|_{\text {aut }} \equiv Q_{\text {aut }}=\frac{N_{l}}{q_{l}} \frac{d q_{l}}{d t} \\
& =-\gamma 10^{3} \rho_{\text {air }} \times 1350\left(\frac{1}{10^{3} \rho_{\text {air }}}\right)^{2.47} q_{l}^{1.47} N_{l}^{-0.79}
\end{aligned}
$$

Here the liquid water content $q_{l}$ has to be given in $\mathrm{g} \mathrm{m}^{-3}$, the cloud droplet number concentration $N_{l}$ in $\mathrm{cm}^{-3}$, and the air density $\rho_{\text {air }}$ in $\mathrm{kg} \mathrm{m}^{-3}$. The constant 1350 has been obtained by Khairoutdinov and Kogan (2000) from a fit to results from an explicit microphysics model. $\gamma$ is a model tuning parameter, as described below.

This parameterization has the disadvantage of not providing a term for selfcollection, i.e. cloud droplet growth which does not lead to precipitation yet. As previous studies (Flossmann et al., 1985; Ivanova and Leighton, 2008) have shown 
that droplet collision-coalescence leads to important redistributions of the in-droplet aerosol, we revert to the following parameterization by Beheng (1994) in order to include this process.

$$
\begin{aligned}
& \left.\frac{d q_{l}}{d t}\right|_{\text {aut }}=-\gamma 10^{6} \times 6 \times 10^{25} n^{-1.7}\left(\frac{q_{l}}{10^{6}}\right)^{4.7} N_{l}^{-3.3} \\
& \left.\frac{d N_{l}}{d t}\right|_{\text {aut }+ \text { self }} \equiv Q_{\text {aut }}+Q_{\text {self }} \\
& =\left.7.7 \frac{d q_{l}}{d t}\right|_{\text {aut }}+Q_{\text {self }} \\
& =-\gamma 7.7 \times 6 \times 10^{25} n^{-1.7}\left(\frac{q_{l}}{10^{6}}\right)^{4.7} N_{l}^{-3.3} \\
& -5.5 \times 10^{10} n^{-0.63}\left(10^{-6} q_{l}\right)^{2}
\end{aligned}
$$

The coefficients, derived by Beheng (1994) from the stochastic collection equation, are valid for $q_{l}$ in $\mathrm{g} \mathrm{m}^{-3}$ and $N_{l}$ in $\mathrm{cm}^{-3} . \quad n=10$ is the width parameter of the initial droplet spectrum. Beheng's (1994) scheme was previously used in the ECHAM4 GCM (Lohmann and Roeckner, 1996; Lohmann et al., 1999). The parameter $\gamma$ is used to scale the conversion of cloud liquid water to rain in such a way that a balanced radiation budget at the top of the atmosphere is achieved. A higher value of $\gamma$ increases precipitation formation and lowers the global mean droplet number concentration and liquid water path, therefore decreasing the reflected shortwave radiation. This tuning is necessary and justified because subgrid-scale variations in the cloud droplet number concentration can not be resolved in global models, but can have a strong impact on the nonlinear process of rain formation. For the sensitivity simulations in Table $2, \gamma$ ranges between 20 and 400 . While other parameters (e.g., related to ice phase microphysics) could have been adjusted to bring the model into a radiative balance, too, we have restricted the tuning to the modification of $\gamma$ because this simplifies the interpretation of results and because this process is directly coupled to changes in aerosol concentrations.

Cloud droplet activation is the most important process of uptake of aerosol particles into hydrometeors. Lin and Leaitch's (1997) activation parameterization, which is used by Lohmann et al. (2007), is not suitable for treating nucleation scavenging explicitly, as explained below. It has therefore been replaced by Ghan et al.'s (1993) activation parameterization. These two activation schemes are compared in Fig. 3.

$$
\begin{aligned}
& N_{l, \text { Lin and Leaitch }(1997)}=0.1 \times\left(\frac{w N_{\text {aer }>35 \mathrm{~nm}}}{w+\alpha N_{\text {aer }>35 \mathrm{~nm}}}\right)^{1.27} \\
& \text { with } w=\bar{w}+1.3 \sqrt{\mathrm{TKE}} \\
& N_{l, \text { Ghan }(1993)}=\frac{w N_{\text {aer }>35 \mathrm{~nm}}}{w+\beta N_{\text {aer }>35 \mathrm{~nm}}} \\
& \text { with } w=\bar{w}+0.7 \sqrt{\mathrm{TKE}}
\end{aligned}
$$

The coefficients $\alpha$ and $\beta$ are set to $\alpha=0.023 \mathrm{~cm}^{4} \mathrm{~s}^{-1}$ and $\beta=0.0034 \mathrm{~cm}^{4} \mathrm{~s}^{-1}$. The updraft velocity $w$ (in $\mathrm{cm} \mathrm{s}^{-1}$ ) is obtained from the large-scale vertical velocity $\bar{w}$ and a turbulent contribution, estimated from the turbulent kinetic energy TKE. The turbulent contribution is larger for Lin and Leaitch's (1997) parameterization because this approach requires the maximum updraft velocity. $N_{l}$ is the cloud droplet number in $\mathrm{cm}^{-3}$, and $N_{\text {aer }}>35 \mathrm{~nm}$ is the number of aerosol particles larger than $35 \mathrm{~nm}$ in $\mathrm{cm}^{-3}$. Figure 3 shows the substantially different results of these two activation parameterizations at low aerosol concentrations. While in Ghan et al.'s (1993) parameterization, nearly all aerosol particles are activated if their concentration is low, Lin and Leaitch's (1997) parameterization predicts substantial droplet concentrations only for $N_{\text {aer }>35 \mathrm{~nm}}>100 \mathrm{~cm}^{-3}$. At lower aerosol concentrations, Lin and Leaitch (1997) predicts nearly no activation, which is unphysical. The number of activated droplets in this case is set to an empirical minimum value of $40 \mathrm{~cm}^{-3}$ (Lohmann et al., 2007). As the mass and number of activated particles is transferred to the in-cloud mode in the aerosol processing scheme, Ghan et al.'s (1993) parameterization is preferred, because the contribution of the different aerosol modes to the activated particles can be directly calculated also at low aerosol concentrations.

Simulation AP includes the new explicit treatment of aerosol processing. Through processes discussed below, global and annual mean aerosol particle and droplet number concentrations are considerably higher in this simulation. Consequently, in the global and annual mean clouds are more reflective, leading to an imbalance of the net radiation at the top of the atmosphere. In simulation AP, this has been corrected for with an increased $\gamma$. Simulation AP will be compared to simulation CTL in the subsequent discussion.

Further sensitivity studies include an improved, more physical treatment of below-cloud scavenging after Croft et al. (2008a) (simulation AP-bcs), an artificial reduction of the water uptake on sea salt aerosols (simulation APaod), rather high but still plausible collision coefficients for accumulation and coarse mode particles (simulation APcoll), and all three sensitivity tests combined (simulation AP-comb). In Croft et al.'s (2008a) below-cloud scavenging scheme (simulation AP-bcs), the scavenging coefficients are calculated by integrating over the rain drop and aerosol size distributions, as opposed to fixed below-cloud scavenging coefficients in standard ECHAM5-HAM. In simulation AP-aod, water uptake by sea salt aerosols has artificially been reduced by a factor of 2 , in order to investigate the extent to which the hygroscopic growth of the particles contributes to the aerosol optical thickness over the ocean. For in-cloud impaction scavenging, the collision kernels are taken from Young (1974) for growing droplets in simulation AP (Hoose et al., 2008), which have low values especially for the accumulation and coarse modes. In simulation AP-coll, the collision kernels are taken from Young (1974) for evaporating droplets instead, and additionally have been multiplied 

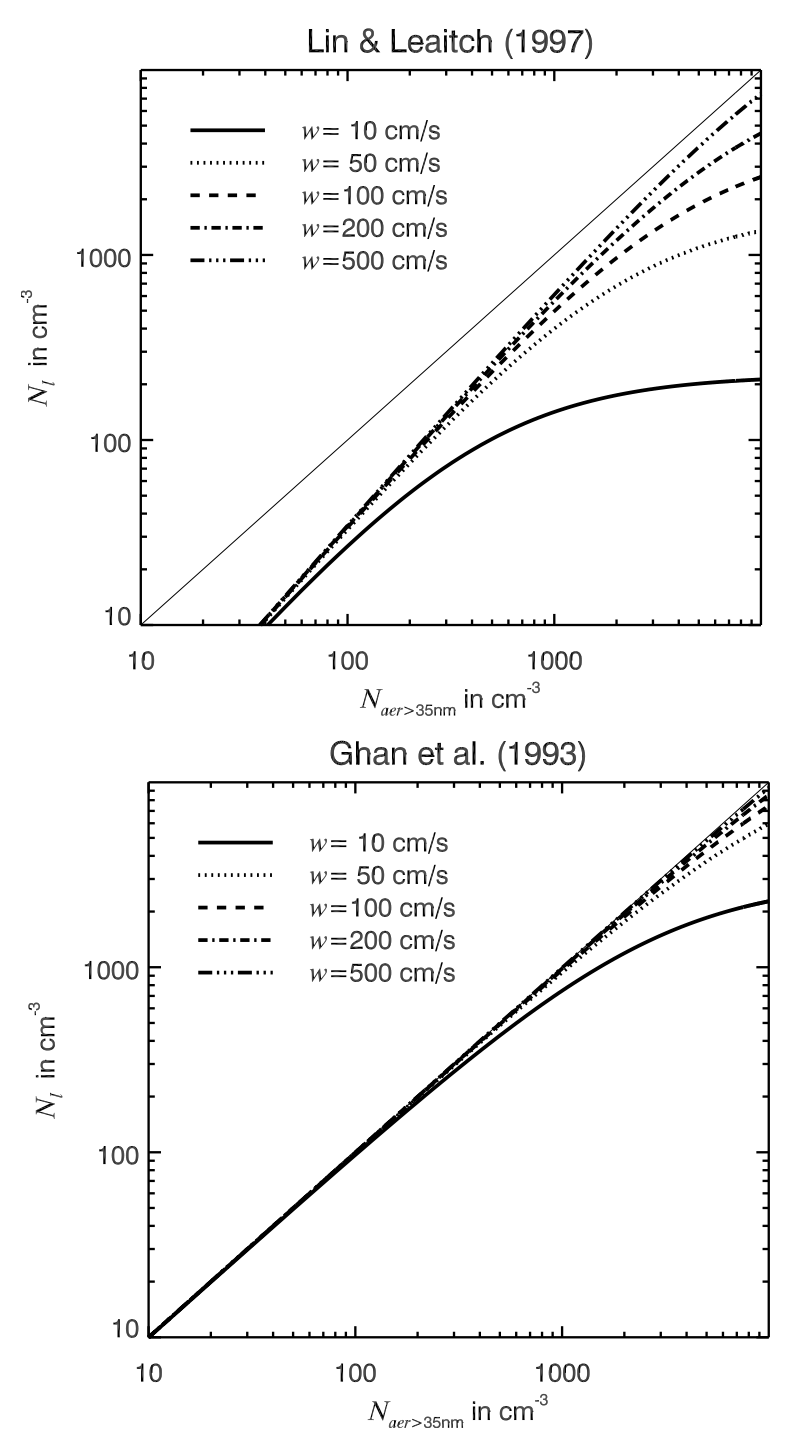

Fig. 3. Concentration of activated cloud droplets $N_{l}$ as a function of aerosol particles with a dry radius $>35 \mathrm{~nm}$ and of the vertical velocity $w$, as in the parameterizations by Lin and Leaitch (1997) and Ghan et al. (1993).

by a factor of $10^{3}$ for the accumulation and coarse modes as a sensitivity study. The collision kernels are higher for evaporating droplets, because thermophoresis enhances the diffusive transport of aerosol particles towards the droplets. Although the multiplication by a factor of $10^{3}$ is a large change, the resulting collision coefficients still lie at the upper end of the range of the size-dependent collision kernels between aerosols and droplets computed by Croft et al. (2008b), which vary over several orders of magnitude.

All simulations have been integrated for 5 years in resolution T42, with 19 vertical levels, a timestep of $15 \mathrm{~min}$ and a model spin-up of 3 months.

\section{Comparison to the standard model}

\subsection{Global and zonal mean cloud and aerosol parameters}

Table 3 gives an overview over global annual mean values of cloud-related variables. The global mean liquid water path is $63 \mathrm{~g} \mathrm{~m}^{-2}$ in simulation CTL, and $44 \mathrm{~g} \mathrm{~m}^{-2}$ in simulation AP. As can be seen in Fig. 4, CTL lies in the upper range of values retrieved from satellite data over oceans (O'Dell et al., 2008; Greenwald et al., 1993) except for the tropics, while AP follows more closely the retrieval by Weng et al. (1997). The satellite retrievals stem from the same data source (the Special Sensor Microwave Imager SSM/I), but cover different time spans and the algorithms differ among other things with respect to the cloud-rain partitioning and sea ice screening. The precipitation screening in the climatologies by Greenwald et al. (1993) and Weng et al. (1997) is likely to cause an underestimate of the LWP. O'Dell et al. (2008) include additional data from the Tropical Rainfall Measurement Mission (TRMM) Microwave Imager and the Advanced Microwave Scanning Radiometer for Earth $\mathrm{Ob}$ servering System (AMSR-E), and explicitly solve for the diurnal cycle of cloud liquid water. The ice water path is similar in all simulations $\left(\approx 20 \mathrm{~g} \mathrm{~m}^{-2}\right)$, which is somewhat lower than an estimate from ISCCP data by Storelvmo et al. (2008) of $29 \mathrm{~g} \mathrm{~m}^{-2}$. The shortwave cloud forcing (SCF) is $-55.8 \mathrm{~W} \mathrm{~m}^{-2}$ in simulation CTL and $-51.1 \mathrm{~W} \mathrm{~m}^{-2}$ in simulation AP, compared to ERBE retrievals (Kiehl and Trenberth, 1997) of $-50 \mathrm{~W} \mathrm{~m}^{-2}$. Figure $4 \mathrm{~b}$ illustrates that the zonal distribution of the SCF is well captured in both simulations. The longwave cloud forcing, which depends mainly on ice clouds, is similar in all simulations and close to the observed value of approximately $30 \mathrm{~W} \mathrm{~m}^{-2}$. An equilibrated radiation budget $\left(F_{\text {net }} \approx 0\right)$ is achieved in all simulations by adjusting the autoconversion tuning parameter.

Figure $4 \mathrm{c}$ reveals that the aerosol optical depth (AOD) is significantly higher in simulation AP (global mean 0.42) than in simulation CTL (0.18) and as obtained from combined multiannual satellite and sun-photometer observations (0.15-0.19) (Kinne, 2008). CTL agrees generally well with the observations, but overestimates the AOD at southern latitudes. Overestimation of aerosol optical depth can be due to several reasons: too high aerosol mass burdens, incorrectly simulated aerosol size distributions or incorrect assumptions about the aerosol optical properties. For example, too large aerosol particles or an overestimation of aerosol water uptake can result in an overestimation of AOD. The aerosol burden and size distribution are significantly different with the new treatment of aerosol processing, as discussed below.

Despite the differences in the atmospheric aerosol, the droplet number burden $N_{l}^{\mathrm{B}}$ is similar in simulations $\mathrm{AP}$ and CTL (grid-mean values of $4.7 \times 10^{10} \mathrm{~m}^{-2}$ and $4.2 \times 10^{10} \mathrm{~m}^{-2}$ ). The tuning of the autoconversion rate has lead to the reduction of $N_{l}^{\mathrm{B}}$ in simulation AP, which otherwise would be higher than in simulation CTL. The global 
(a) LWP over oceans in $\mathrm{g} \mathrm{m}^{-2}$

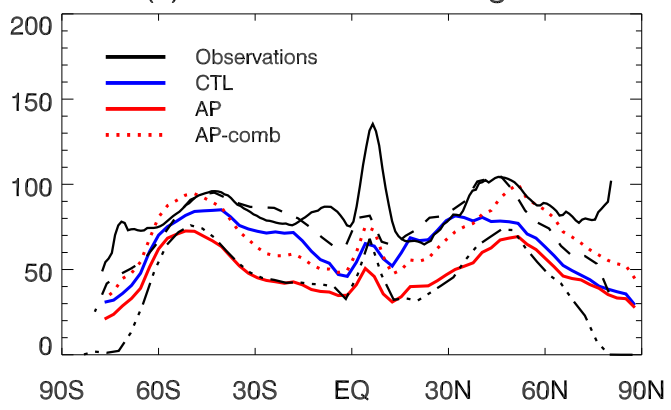

(c) AOD

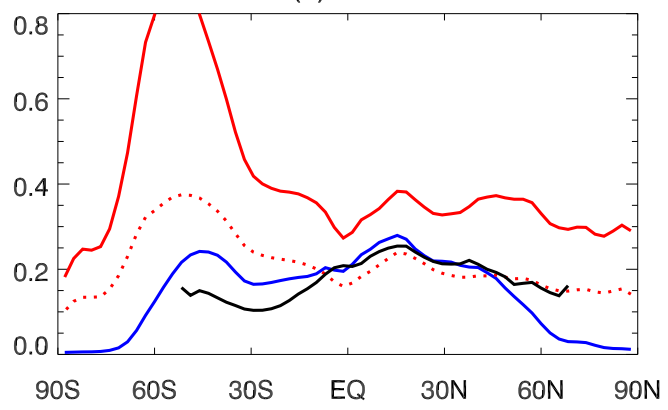

(b) SW cloud forcing in $\mathrm{W} \mathrm{m}^{-2}$

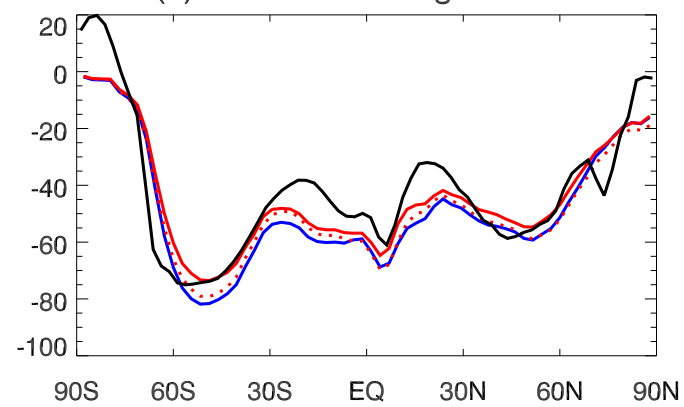

(d) $N_{l \text {, cloudy }}^{\mathrm{B}}$ in $10^{10} \mathrm{~m}^{-2}$

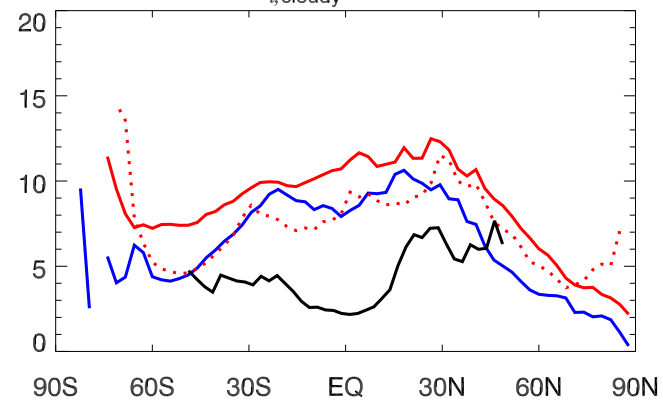

Fig. 4. Annual zonal mean (a) liquid water path over oceans, (b) shortwave cloud forcing, (c) aerosol optical depth, and (d) cloud droplet number burden in cloudy areas from simulations CTL, AP and AP-comb. Black lines are different satellite observations: (a) SSM/I retrievals by O'Dell et al. (2008) (continuous line), Greenwald et al. (1993) (dashed line) and Weng et al. (1997) (dash-dotted line), (b) ERBE measurements (Kiehl and Trenberth, 1997), (c) a multi-annual combined satellite/AERONET composite (Kinne, 2008), and (d) a retrieval based on ISCCP data (Han et al., 1998).

mean precipitation rate is mainly determined by the evaporation rate from oceans, which is fixed by the prescribed sea surface temperatures. Therefore it is similar in all simulations (around $2.86 \mathrm{~mm} \mathrm{~d}^{-1}$ ), which is slightly higher than the observational estimate by Adler et al. (2003) of $2.74 \mathrm{~mm} \mathrm{~d}^{-1}$.

In a previous publication (Lohmann et al., 2007), $N_{l}^{\mathrm{B}}$ has been compared to a retrieval by Han et al. (1998). Han et al. (1998) obtain a global mean droplet burden of $4 \times 10^{10} \mathrm{~m}^{-2}$, but this value refers to an average over cloudy pixels with liquid cloud tops only $\left(N_{l, \text { cloudy }}^{\mathrm{B}}\right)$. The analogous calculation for the simulations yields higher values of $7.6 \times 10^{10} \mathrm{~m}^{-2}$ (CTL) and $9.5 \times 10^{10} \mathrm{~m}^{-2}(\mathrm{AP})$.

Global aerosol sources, burdens and lifetimes are given in Table 4. For comparison, values from a previous version of ECHAM5-HAM (Stier et al., 2005) and AeroCom all-models averages (Textor et al., 2006) are included. ECHAM5-HAM emissions of sulfate precursors, black carbon and organic carbon are prescribed. Therefore between the simulations CTL, AP and the one described in Stier et al. (2005), sulfate, black carbon and organic carbon sources differ only with respect to the conversion of $\mathrm{SO}_{2}$ to sulfate, which depends on atmospheric parameters. Sea salt and mineral dust emissions depend on the simulated wind field, and are higher in both CTL and AP than in Stier et al.'s (2005) study. Differences between our model and ECHAM5-HAM as used by Stier et al. (2005) include the resolution (T42 versus T63), the mode of operation (climatological versus nudged mode), and several differences in the cloud scheme. Stier et al.'s (2005) simulation was run with a single-moment cloud scheme (Lohmann and Roeckner, 1996) and with a statistical cloud cover parameterization (Tompkins, 2002). The simulations presented here include double-moment cloud microphysics (Lohmann et al., 2007), and the cloud cover calculation is based on relative humidity (Sundqvist et al., 1989). It has been shown in a study with the ECHAM4 GCM that simulated mineral dust emissions in the climatological mode are about $25 \%$ higher than if the model is nudged to wind fields from a reanalysis (Timmreck and Schulz, 2004), a possible explanation for the difference in our simulations and Stier et al. (2005). Sea salt and mineral dust emissions in AP are different from simulation CTL, because aerosol feedbacks on clouds can result in a different model "weather" with modified surface windspeeds and soil moisture (not shown).

All ECHAM5-HAM simulated emissions except for sulfate are lower than the AeroCom all-models average. For sea salt and mineral dust, supercoarse particles (with a radius 
Table 4. Global annual mean sources, burden and lifetimes in simulations CTL and AP and previous studies. The components are $\mathrm{SO}_{4}=$ (condensed) sulfate, $\mathrm{SO}_{4}(\mathrm{~g})=$ gaseous sulfuric acid, $\mathrm{SO}_{2}=$ gaseous sulfur dioxide, $\mathrm{BC}=$ black carbon, $\mathrm{OC}=$ organic carbon, $\mathrm{SS}=$ sea salt, DU=dust. The abbreviations of the modes are listed in Table 1. The number burdens are not provided by Stier et al. (2005) and Textor et al. (2006).

\begin{tabular}{|c|c|c|c|c|c|}
\hline & & CTL & $\mathrm{AP}$ & $\begin{array}{l}\text { ECHAM5-HAM } \\
\text { (Stier et al., 2005) }\end{array}$ & $\begin{array}{l}\text { AeroCom } \\
\text { all-models mean } \\
\text { (Textor et al., 2006) }\end{array}$ \\
\hline $\mathrm{SO} 4$ & sources in $\operatorname{Tg}(\mathrm{S}) \mathrm{yr}^{-1}$ & 75.9 & 75.5 & 76.1 & 59.7 \\
\hline $\mathrm{BC}$ & sources in $\mathrm{Tg} \mathrm{yr}^{-1}$ & 7.7 & 7.7 & 7.7 & 11.9 \\
\hline $\mathrm{OC}$ & sources in $\mathrm{Tg} \mathrm{yr}^{-1}$ & 66.1 & 66.1 & 66.1 & 96.6 \\
\hline SS & sources in $\mathrm{Tg} \mathrm{yr}^{-1}$ & 6446 & 6494 & 5032 & 16600 \\
\hline DU & sources in $\mathrm{Tg} \mathrm{yr}^{-1}$ & 722 & 719 & 662 & 1840 \\
\hline $\mathrm{SO} 4$ & burden in $\operatorname{Tg}(S)$ & 0.83 & 0.99 & 0.80 & 0.67 \\
\hline $\mathrm{BC}$ & burden in $\mathrm{Tg}$ & 0.12 & 0.14 & 0.11 & 0.24 \\
\hline $\mathrm{OC}$ & burden in $\mathrm{Tg}$ & 1.08 & 1.19 & 0.99 & 1.7 \\
\hline SS & burden in $\mathrm{Tg}$ & 11.7 & 16.3 & 10.5 & 7.5 \\
\hline DU & burden in $\mathrm{Tg}$ & 8.0 & 14.2 & 8.3 & 19.2 \\
\hline $\mathrm{SO} 4$ & lifetime in days & 4.0 & 4.8 & 3.9 & 4.1 \\
\hline $\mathrm{BC}$ & lifetime in days & 5.7 & 6.6 & 5.4 & 7.4 \\
\hline $\mathrm{OC}$ & lifetime in days & 6.0 & 6.6 & 5.4 & 6.4 \\
\hline SS & lifetime in days & 0.7 & 0.9 & 0.8 & 0.2 \\
\hline DU & lifetime in days & 4.0 & 7.2 & 4.6 & 3.8 \\
\hline$N_{\mathrm{NS}}$ & burden in $10^{10} \mathrm{~m}^{-2}$ & 21872 & 29726 & & \\
\hline$N_{\mathrm{KS}}$ & burden in $10^{10} \mathrm{~m}^{-2}$ & 812 & 610 & & \\
\hline$N_{\text {AS }}$ & burden in $10^{10} \mathrm{~m}^{-2}$ & 69 & 115 & & \\
\hline$N_{\mathrm{CS}}$ & burden in $10^{10} \mathrm{~m}^{-2}$ & 0.65 & 0.45 & & \\
\hline$N_{\mathrm{KI}}$ & burden in $10^{10} \mathrm{~m}^{-2}$ & 8.8 & 6.4 & & \\
\hline$N_{\mathrm{AI}}$ & burden in $10^{10} \mathrm{~m}^{-2}$ & 0.09 & 0.17 & & \\
\hline$N_{\mathrm{CI}}$ & burden in $10^{10} \mathrm{~m}^{-2}$ & 0.16 & 0.33 & & \\
\hline
\end{tabular}

larger than a few micrometers), which contribute significantly to the emissions in some AeroCom models, but have a short atmospheric residence time, are not included in ECHAM5-HAM.

The aerosol mass burden for all species is larger in AP than in CTL. Consequently, the aerosol lifetimes, listed for the five components in Table 4, are longer in simulation AP. The particle number burdens are significantly higher with the explicit treatment of aerosol processing for the nucleation, soluble accumulation and insoluble accumulation and coarse modes. In simulation AP, insoluble particles are only scavenged by collisions with hydrometeors, a relatively inefficient process for large particles. Nucleation scavenging is also negligible for the nucleation mode. Also for the accumulation mode nucleation scavenging is not as efficient in simulation AP as assumed with the fixed ratios of Stier et al. (2005) used in the CTL simulation. The soluble coarse mode burden $N_{\mathrm{CS}}$ is lower in simulation AP than in simulation CTL, because these particles are more efficiently scavenged in both liquid and ice clouds as compared to simulation CTL.

\section{In-cloud aerosol budgets}

Differences in the aerosol lifetime, burden, the aerosol optical depth, and consequently in the cloud droplet concentrations and further cloud parameters are caused by the different treatment of in-cloud aerosol in simulations CTL and AP. Differences in the wet removal of particles from the atmosphere have a high impact on these results, as shown below.

\subsection{Scavenged aerosol mass}

The scavenged fraction, i.e. the fraction of total aerosol mass or number which is incorporated in hydrometeors and is removed from the atmosphere when precipitation forms, is prescribed to fixed values for the seven modes and for three temperature ranges in the ECHAM5-HAM standard version (Stier et al., 2005). For stratiform liquid clouds, these parameters range from 0.1 for the nucleation mode to 0.99 for the mixed coarse mode (see Table 1 and Fig. 2). With the prognostic treatment of in-cloud particles, the scavenged mass depends on the history of the cloud (vertical velocities at 

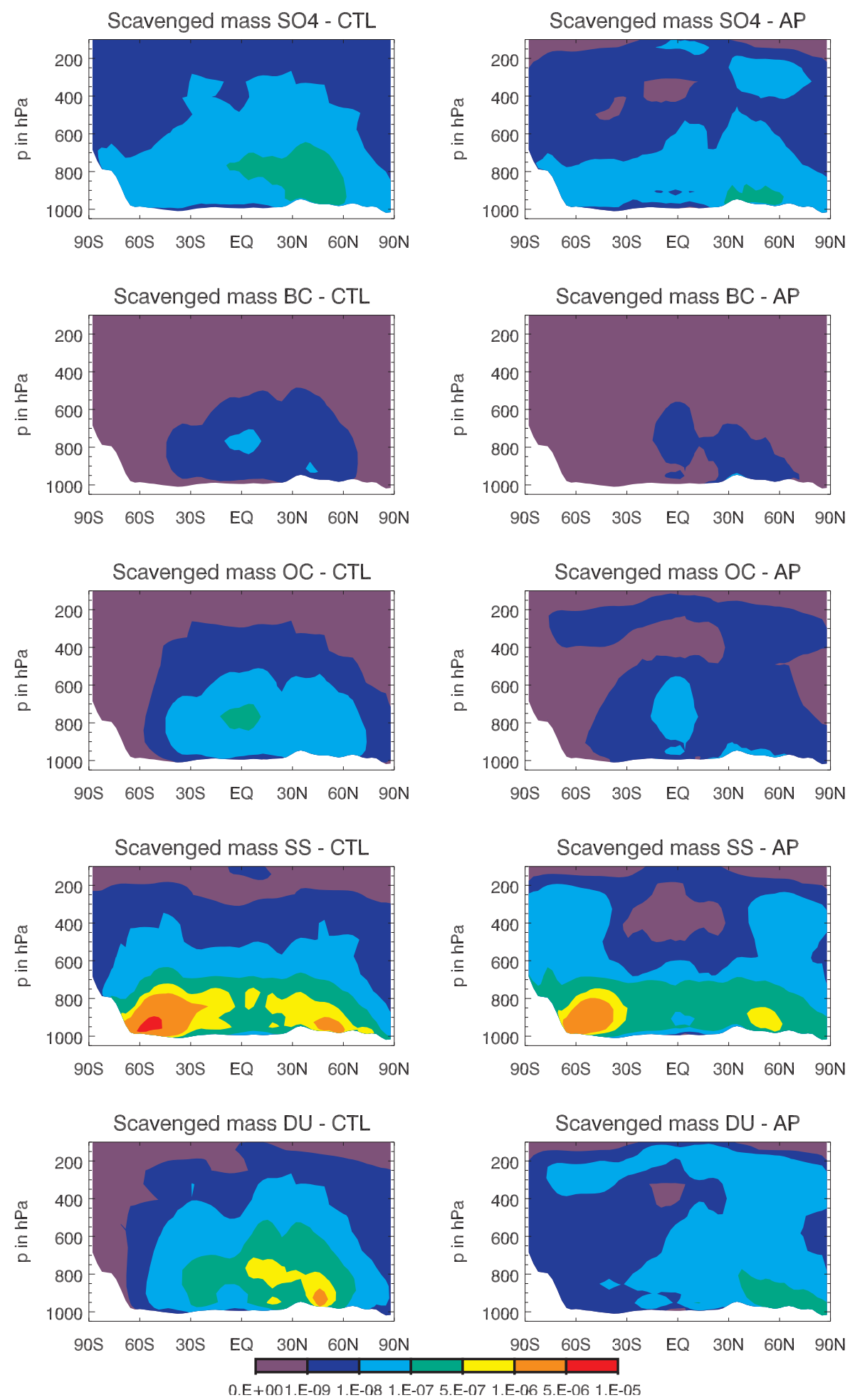

Fig. 5. Zonal and annual mean scavenged aerosol mass, diagnosed from simulation CTL (left), and simulated in simulation AP (right), in $\mu \mathrm{g}$ $\mathrm{m}^{-3}$. 
cloud base, time available for collision scavenging, WegenerBergeron-Findeisen process).

Figure 5 compares the scavenged aerosol mass from the simulation CTL, diagnosed with the fixed scavenging parameters, to the prognostic in-droplet and in-crystal mass in simulation AP. The scavenged aerosol masses are in general smaller in simulation AP than in CTL, except at high altitudes. In the ice-cloud levels above approximately $400 \mathrm{hPa}$, most of the available aerosol mass is in-cloud in simulation $\mathrm{AP}$, because the large soluble aerosol particles are assumed to freeze homogeneously (Hoose et al., 2008; Kärcher and Lohmann, 2002). In contrast, in CTL, the scavenged mass fraction in ice clouds is assumed to be only 0.1 for all modes.

At lower levels, the scavenged mass is similar in both simulations for sulfate, which is due to the large fraction of sulfate that is formed in the droplets. For black carbon and organic carbon, the scavenged mass is considerably smaller in simulation AP than in CTL, because the carbon particles are generally small and therefore less frequently activate to cloud droplets. Collision scavenging, though of some importance at these particle sizes, can not compensate for the low nucleation scavenging. Sea salt, although it is in the size range of particles which activate easily, is not scavenged to the same extent as with the prescribed scavenging ratios in the CTL simulation. This occurs since the scavenged aerosol fraction depends on the history of the cloud in simulation AP, unlike in CTL. If precipitation removes in-droplet aerosol particles, the scavenged fraction is not refilled in simulation AP, unless new nucleation occurs. In simulation CTL, the same high scavenged fraction is applied at every timestep, without any dependence on the cloud history. This results in high average scavenged aerosol fractions. For mineral dust, about half of the mass is in the insoluble modes, which are not assumed to activate to cloud droplets at all (Hoose et al., 2008; Lohmann, 2008), and collision scavenging is negligible for the coarse modes. In simulation CTL, on the other hand, $40 \%$ of the insoluble dust is assumed to be scavenged in clouds at temperatures warmer than $-35^{\circ} \mathrm{C}$. Therefore the scavenged mass is lower by a factor of approximately 5 with the prognostic treatment in simulation AP. This results in a more than twofold increase of the insoluble accumulation and coarse mode particle number burdens (Table 3).

\subsection{Transfer rates between in-cloud and interstitial modes}

Figure 6 illustrates the source and sink terms for aerosol in the interstitial, in-droplet and in-crystal modes, calculated from simulation AP. Sulfate differs from the other aerosol components in that it is mainly formed within the atmosphere. It can either nucleate directly from the gas phase (negligible for the mass budget, but important for particle numbers), condense on pre-existing interstitial particles, or form by heterogeneous reactions in the aqueous phase, in which case it is attributed to the in-droplet mode. The incloud formation is the main source $(68 \%$ of the total mass production) of atmospheric sulfate. Therefore, release of particles from evaporating hydrometeors is the most important source of interstitial sulfate (Fig. 6, upper left plot). For black carbon and organic carbon, release during evaporation is roughly as important as the primary emissions. However, these two processes occur at different altitudes: within the atmosphere (release from evaporating hydrometeors) versus only in the two lowest model layers (emissions). The source term at higher altitudes can have a bigger impact, because aerosol mass concentrations and their sinks generally decrease with altitude. Sea salt and dust are emitted from the surface as large particles. Sedimentation is an important removal process for them and can eliminate coarse-mode particles after a short lifetime before interaction with clouds. Smaller interstitial particles are more likely to be removed from the interstitial phase when cloud droplets or ice crystals nucleate on them, or by below-cloud and convective wet deposition. Collisions with cloud droplets or ice crystals are only significant for black carbon and organic carbon, which constitute the insoluble Aitken mode.

The relative contributions from in-cloud sulfate formation, droplet nucleation and collision scavenging are shown in the middle column of Fig. 6. The contributions of the sink terms for in-droplet particles vary noticeably. Sea salt, sulfate, and carbonaceous aerosols are more likely to be removed by wet deposition than mineral dust. This is related to the geographic origins of the clouds into which the particles are incorporated; e.g. clouds in a marine environment, with fewer droplets, can form precipitation faster than polluted continental clouds.

Aerosol mass is incorporated into in-crystal particles largely by ice nucleation (Fig. 6, right column), and removed by sublimation of ice crystals or by precipitation formation. Freezing of cloud droplets is a negligible contribution to the in-crystal aerosol mass. Only a low number of droplets freezes in mixed-phase clouds, while the majority subsequently evaporates during the Wegener-Bergeron-Findeisen process.

\subsection{Life cycles of cloud condensate and in-cloud aerosol}

In this section we compare the time scales of processing of water vapor and aerosols by clouds, as simulated by ECHAM5-HAM with the above-described aerosol processing scheme, to simple calculations by Pruppacher and Jaenicke (1995). Pruppacher and Jaenicke (1995) based their estimates of these time scales on global mean values of cloud parameters (cloud cover, liquid water content, vertical velocities and others) for different cloud types. The considered aerosol is not further specified by Pruppacher and Jaenicke (1995). Selected results are summarized in Table 5. Their value for the global mean liquid water path (LWP) is very high with $388 \mathrm{~g} \mathrm{~m}^{-2}$, based on Lelieveld et al. (1989). Current estimates from satellite retrievals over ocean range between 48-86 $\mathrm{g} \mathrm{m}^{-2}$ (O’Dell et al., 2008; Weng et al., 1997; 
Table 5. Global budgets of cloud water and aerosols. P\&J stands for Pruppacher and Jaenicke (1995). LWP: liquid water path, TWP: total water path (given in the last column only), $P$ : precipitation, $C_{\mathrm{v}, \mathrm{c}}$ : rate of condensation of water vapor mass, $E_{\mathrm{v}, \mathrm{in} \text {-cloud }}:$ rate of in-cloud evaporation of water mass, $E_{\mathrm{v}, \mathrm{c}}$ : rate of in-cloud evaporation of cloud water mass plus below-cloud evaporation of precipitation, $\tau_{\mathrm{c}, \text { precip }}$ : cloud lifetime with respect to precipitation, $\tau_{\mathrm{c}, \text { evap }}$ : cloud lifetime with respect to evaporation, $C_{\mathrm{AP}, \mathrm{c}}$ : rate of aerosol mass transferred into clouds, $E_{\mathrm{AP} \text {,in-cloud }}$ rate of aerosol mass release from evaporating clouds, $E_{\mathrm{AP}, \mathrm{c}}$ : rate of aerosol mass release from evaporating clouds and evaporating precipitation, $W_{\mathrm{dep}, \mathrm{ic}}$ : in-cloud wet deposition of aerosol mass, $W_{\mathrm{dep}, \mathrm{bc}}$ : below-cloud wet deposition of aerosol mass, $W_{\mathrm{dep}}$ : total wet deposition of aerosol mass, $S_{\mathrm{AP}}$ : source strength of aerosols on the ground.

\begin{tabular}{|c|c|c|c|c|}
\hline & $\begin{array}{l}\text { P\&J, convective and } \\
\text { stratiform clouds }\end{array}$ & $\begin{array}{l}\text { P\&J, recalculated } \\
\text { for stratiform } \\
\text { clouds only }\end{array}$ & $\begin{array}{l}\text { AP, stratiform } \\
\text { liquid clouds }\end{array}$ & $\begin{array}{l}\text { AP, stratiform liquid, } \\
\text { mixed-phase and } \\
\text { ice clouds }\end{array}$ \\
\hline LWP (TWP) in $\mathrm{gm}^{-2}$ & 388 & 136 & 44 & 64 \\
\hline$P$ in $\mathrm{mm} \mathrm{yr}^{-1}$ & 1000 & 500 & $211^{\mathrm{a}}$ & 479 \\
\hline$P$ in $\mathrm{g} \mathrm{m}^{-2} \mathrm{~h}^{-1}$ & 114 & 57 & $24^{\mathrm{a}}$ & 55 \\
\hline$C_{\mathrm{V}, \mathrm{c}}$ in $\mathrm{g} \mathrm{m}^{-2} \mathrm{~h}^{-1}$ & 1256 & 206 & 97 & 155 \\
\hline$E_{\mathrm{v}, \text { in-cloud }}$ in $\mathrm{g} \mathrm{m}^{-2} \mathrm{~h}^{-1}$ & & & 54 & 61 \\
\hline$E_{\mathrm{V}, \mathrm{c}}$ in $\mathrm{g} \mathrm{m}^{-2} \mathrm{~h}^{-1}$ & 1142 & 148 & $72^{\mathrm{a}}$ & 100 \\
\hline$\frac{E_{\mathrm{V}, \mathrm{c}}}{C_{\mathrm{v}, \mathrm{c}}}$ & 0.91 & 0.72 & 0.75 & 0.64 \\
\hline$\tau_{\mathrm{c}, \text { precip }}=\frac{\mathrm{LWP}}{P}$ in $\mathrm{h}$ & 3.4 & 2.4 & 1.8 & 1.2 \\
\hline$\tau_{\mathrm{c}, \text { evap }}=\frac{L W \mathrm{P}}{E_{\mathrm{v}, \mathrm{c}}}$ in $\min$ & 21 & 55 & 36 & 38 \\
\hline$C_{\mathrm{AP}, \mathrm{c}}$ in $\mathrm{Tg} \mathrm{yr}^{-1}$ & 6533 & 1072 & 5400 & 5596 \\
\hline$E_{\mathrm{AP}, \text { in-cloud }}$ in $\mathrm{Tg} \mathrm{yr}^{-1}$ & & & 2718 & 2954 \\
\hline$E_{\mathrm{AP}, \mathrm{c}}$ in $\mathrm{Tg} \mathrm{yr}^{-1}$ & 5947 & 775 & 3723 & 4027 \\
\hline$W_{\text {dep ic }}$ in $\mathrm{Tg} \mathrm{yr}^{-1}$ & 586 & 297 & $1533\left(2538^{\mathrm{b}}\right)$ & $1570\left(2643^{b}\right)$ \\
\hline$W_{\text {dep }, \mathrm{bc}}$ in $\mathrm{Tg} \mathrm{yr}^{-1}$ & 146 & 74 & $237\left(400^{\mathrm{b}}\right)^{\mathrm{d}}$ & $237\left(400^{\mathrm{b}}\right)$ \\
\hline$W_{\mathrm{dep}}^{\mathrm{d}}$ in $\mathrm{Tg} \mathrm{yr}^{-1}$ & 732 & 371 & $1789^{\mathrm{c}}$ & 1826 \\
\hline$S_{\mathrm{AP}}$ in $\mathrm{Tg}_{\mathrm{yr}}{ }^{-1}$ & $\approx 2000$ & 2000 & 7576 & 7576 \\
\hline$\frac{E_{\mathrm{AP}, \mathrm{c}}}{C_{\mathrm{AP}, \mathrm{c}}}$ & 0.91 & 0.72 & 0.69 & 0.72 \\
\hline$\frac{E_{\mathrm{AP}, \mathrm{c}}}{S_{\mathrm{AP}}}$ & $\approx 3$ & $\approx 0.4$ & 0.49 & 0.53 \\
\hline
\end{tabular}

${ }^{a}$ under the assumption that the same fractions of precipitation from liquid clouds and of melted precipitation from mixed-phase/ice clouds evaporate below-cloud

$\mathrm{b}$ before below-cloud evaporation of precipitation

$\mathrm{c}$ includes below-cloud scavenging through precipitation from mixed-phase/ice clouds

$\mathrm{d}$ after below-cloud evaporation

Greenwald et al., 1993). On the other hand, the estimate of global mean precipitation $(P)$ of $1000 \mathrm{~mm} \mathrm{yr}^{-1}$ is in accordance with observations from the Global Precipitation Climatology Project (Adler et al., 2003). Along with the high LWP, Pruppacher and Jaenicke (1995) estimate a high condensation rate $C_{\mathrm{v}, \mathrm{c}}$ of about 11 times the precipitation rate. The evaporation rate $E_{\mathrm{v}, \mathrm{c}}$ is the difference between condensation and (surface) precipitation. This includes below-cloud evaporation. According to Pruppacher and Jaenicke (1995), more than $90 \%$ of the condensed cloud water re-evaporates, rather than forms precipitation which reaches the ground. Therefore the cloud lifetime with respect to precipitation $\left(\tau_{\mathrm{c}, \text { precip }}=3.4 \mathrm{~h}\right)$ is ten times as long as the cloud lifetime with respect to evaporation $\left(\tau_{\mathrm{c}, \text { evap }}=20.5 \mathrm{~min}\right)$.
As Pruppacher and Jaenicke (1995) give the cloud parameters for 5 cloud types separately, we can exclude the convective clouds $\mathrm{Cb}$ (cumulonimbus) and $\mathrm{Cu}$ (cumulus) from the analysis and recalculate the cloud condensate budget for stratiform clouds only. This is necessary for the comparison with the simulations because the aerosol processing implemented in ECHAM5-HAM only takes place in stratiform clouds. Long-lived contributions from convective clouds are considered in the scheme by detrainment of cloud condensate, which is a source for stratiform clouds (Lohmann, 2008). We assume that 50\% of the global precipitation originates from stratiform clouds (based on Tropical Rainfall Measuring Mission (TRMM) satellite precipitation radar observations between $40^{\circ} \mathrm{S}$ and $40^{\circ} \mathrm{N}$, reported by Tost et al., 2006). Following this 

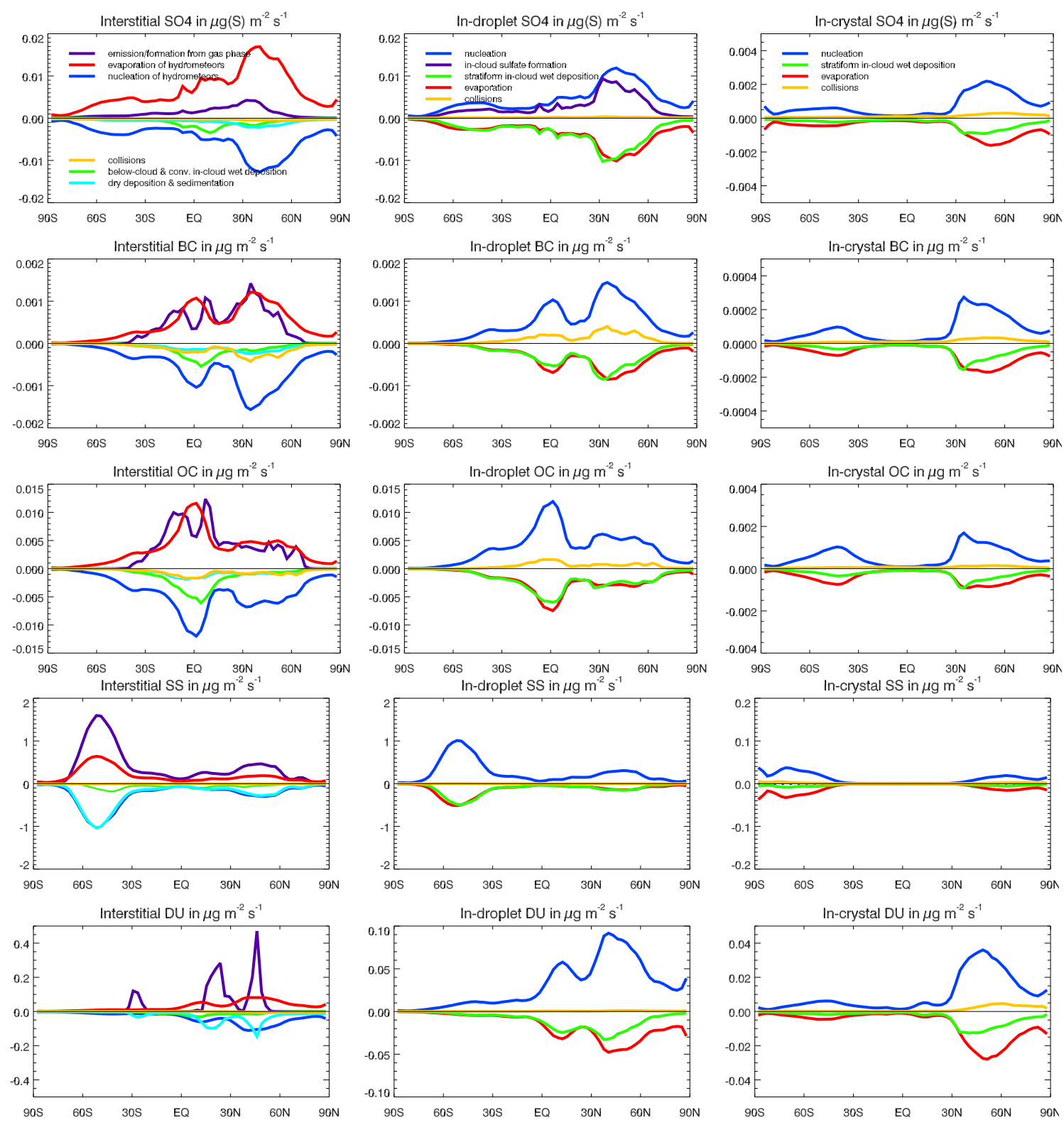

Fig. 6. Annual zonal mean transfer rates for interstitial (left), in-droplet (middle row) and in-crystal (right) aerosol mass, integrated vertically over the atmospheric column. The legend in the upper plots refers to all plots in the respective column. Contributions from freezing and melting are negligible. Note the different scales.

re-calculation, for stratiform clouds only $72 \%$ of the condensate re-evaporates. The lifetime with respect to precipitation is shorter $\left(\tau_{\mathrm{c} \text {, precip }}=2.4 \mathrm{~h}\right)$ and the lifetime with respect to evaporation is longer $\left(\tau_{\mathrm{c}, \text { evap }}=55 \mathrm{~min}\right)$.

ECHAM5-HAM (simulation AP) simulates a substantially lower global mean LWP of stratiform clouds of $44 \mathrm{~g} \mathrm{~m}^{-2}$. $45 \%$ of the modelled global mean precipitation is stratiform. The fraction of this precipitation originating from liquid clouds can only be estimated indirectly, because the diagnostics of below-cloud evaporation does not distinguish between precipitation originating from liquid or mixed- phase/ice clouds. The in-cloud evaporation rate $E_{\mathrm{v}, \text { in-cloud }}$ is diagnosed for liquid and ice separately. For all stratiform clouds, the total (in-cloud plus below-cloud) evaporation rate $E_{\mathrm{v}, \mathrm{c}}$ can be calculated from $C_{\mathrm{v}, \mathrm{c}}-P$. With the fraction of liquid precipitation arriving at the ground, $P_{\text {rain }} /\left(C_{\mathrm{v}, \mathrm{c}}-E_{\mathrm{v}, \text { in }- \text { cloud }}-P_{\text {snow }}\right)=55 \%$, we obtain an estimate of the precipitation from liquid clouds. $75 \%$ of all stratiform cloud water evaporates again, instead of reaching the ground as precipitation. This is in good accordance with Pruppacher and Jaenicke's (1995) value, recalculated for stratiform clouds $(72 \%)$. 
The simulated lifetime with respect to precipitation is $\tau_{\mathrm{c} \text {, precip }}=1.8 \mathrm{~h}$, and the lifetime with respect to evaporation is $\tau_{\mathrm{c}, \text { evap }}=36 \mathrm{~min}$. When mixed-phase and ice clouds are also taken into account, the total water path amounts to $64 \mathrm{~g} \mathrm{~m}^{-2}$. Mixed-phase/ice clouds tend to precipitate more frequently. Therefore the lifetime with respect to precipitation for all stratiform clouds in simulation AP is $1.2 \mathrm{~h}$, and the lifetime with respect to evaporation is $38 \mathrm{~min}$.

For an estimation of the aerosol cycling through clouds, Pruppacher and Jaenicke (1995) assume that aerosol particles are incorporated into clouds and released from them in the same way as water molecules. Furthermore, their calculations are based on a mean aerosol mass concentration of $1 \mu \mathrm{g} \mathrm{m}^{-3}$, and a scavenging efficiency of 1 , i.e. all aerosol particles inside clouds are assumed to be incorporated into hydrometeors. The rate of aerosol mass transferred into clouds, $C_{\mathrm{AP}, \mathrm{c}}$, additionally contains a $30 \%$ contribution of aerosol material converted from gases which have dissolved in the cloud droplets. As for cloud water, the fraction of aerosol particles released from evaporating droplets $\left(E_{\mathrm{AP}, \mathrm{c}}\right)$ is $91 \%$, and only $9 \%$ is removed from the atmosphere by incloud wet deposition $W_{\text {dep,ic }}$. Below-cloud wet deposition ( $W_{\text {dep, bc }}$ ) is assumed to contribute to $20 \%$ to the total aerosol wet deposition. Comparing the rate of aerosol release from evaporating clouds to the aerosol surface source $S_{\mathrm{AP}}$, which is estimated to $\approx 2000 \mathrm{Tg} \mathrm{yr}^{-1}$, yields the number of aerosol cycles through clouds: $E_{\mathrm{AP}, \mathrm{c}} / S_{\mathrm{AP}} \approx 3$. Repeating the calculations for stratiform clouds only gives a fraction of particles released during droplet evaporation of $72 \%$ (same as for cloud condensate). The average number of cycles through stratiform clouds is only approximately 0.4 .

In ECHAM5-HAM, the surface source of aerosol mass is 4 times as large $\left(\approx 7600 \mathrm{Tg} \mathrm{yr}^{-1}\right)$ as estimated by Pruppacher and Jaenicke (1995). Therefore the transfer rates of aerosol mass into clouds, the release rates from evaporating clouds and the wet deposition rates are all considerably larger. Due to the different homogeneous and inhomogeneous mixing assumptions in and below clouds, the ratio of evaporation over condensation for aerosols $\left(E_{\mathrm{AP}, \mathrm{c}} / C_{\mathrm{AP}, \mathrm{c}}=0.69\right.$ and 0.72 , for only liquid and for all stratiform clouds, respectively), is not the same as for cloud condensate $(0.75 / 0.64)$. If inhomogeneous mixing was also assumed for the evaporation of cloud particles, the cycling of aerosols through clouds would probably be accelerated.

Together with the high surface source term, the ratio of $E_{\mathrm{AP}, \mathrm{c}} / S_{\mathrm{AP}}$, which is the mean number of cycles through stratiform clouds experienced by an aerosol particle between its emission from the surface and its deposition, is 0.49 for liquid clouds and 0.53 for all stratiform clouds.

The dimensionless values $E_{\mathrm{v}, \mathrm{c}} / C_{\mathrm{v}, \mathrm{c}}, E_{\mathrm{AP}, \mathrm{c}} / C_{\mathrm{AP}, \mathrm{c}}$ and $E_{\mathrm{AP}, \mathrm{c}} / S_{\mathrm{AP}}$ obtained for all stratiform clouds in simulation AP are similar to Pruppacher and Jaenicke (1995), recalculated for stratiform clouds, although their estimates of the liquid water path and of the aerosol emissions are not in accordance with more recent estimates. The concept of cal- culations based on a global mean value of an aerosol concentration of $1 \mu \mathrm{g} \mathrm{m}^{-3}$ has to be taken with caution. Here model simulations, like simulation AP, can provide more accurate estimates by taking into account the heterogeneity of the aerosol and cloud fields.

\section{Comparison with observations}

Comparisons between global climate model simulations and observations are hampered by the different scales in space and time for which simulated and observed values are representative. If a GCM is not nudged to the synoptic conditions at the observation time, the model results can only be compared as climatological mean values to long timeseries of observations. Furthermore, many observations reflect local conditions, which can vary within a few kilometers, while a GCM gridbox size in T42 resolution is over $300 \mathrm{~km} \times 300 \mathrm{~km}$ at the equator. Here we have chosen several observations of aerosol or cloud microphysical parameters, which cover either large parts of the globe (Sects. 5.1-5.3) or are based on the statistical analysis of clouds sampled under different conditions at one location (Sects. 5.4). The simulations have not been nudged to the meteorological conditions of a specific year, because the observations stem from several different years.

\subsection{Marine boundary layer aerosol}

Heintzenberg et al. (2000) provide a compilation of aerosol concentration and size distribution measurements in the marine boundary layer (MBL). The data include observations from different mobility and aerodynamic sizing techniques, operated at relative humidities of less than $40 \%$. A multimodal lognormal size distribution was fitted to the original data, and from this the number concentrations and dry mean diameters of the Aitken and accumulation modes are given as zonal mean values. These observations are compared to the ECHAM5-HAM simulations CTL and AP in Figs. 7 and 8. The model data were averaged over the surface level at all ocean gridpoints. The soluble and insoluble mode number concentrations are summed up, and the dry diameters are calculated as a weighted average between soluble and insoluble modes.

While the Aitken mode zonal mean number concentrations are slightly lower in AP than in CTL, the accumulation mode number concentrations are significantly higher. The Aitken mode concentrations in both simulations are reasonably close to observations on the Northern Hemisphere, but too low between 15 and $60^{\circ} \mathrm{S}$. This can be possibly due to an underestimation of aerosol nucleation in the boundary layer and to a potential overestimation of the condensational sink for gaseous sulfate, as suggested by Stier et al. (2005). The accumulation mode number concentrations in simulation AP agree better with the observations between $45^{\circ} \mathrm{S}$ and $45^{\circ} \mathrm{N}$, 

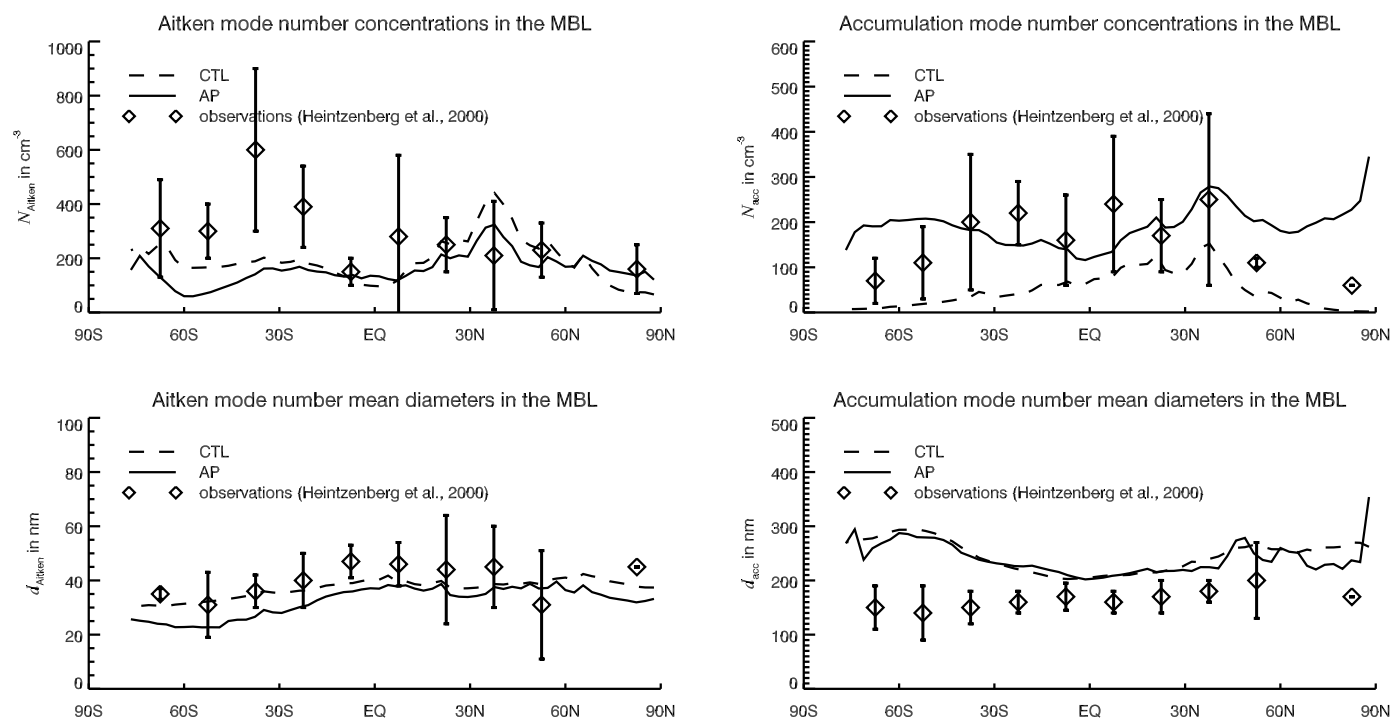

Fig. 7. Aitken and accumulation mode number concentrations and number mean diameters over the oceans, averaged over zonal bands, in simulations CTL and AP, compared to observations compiled by Heintzenberg et al. (2000).
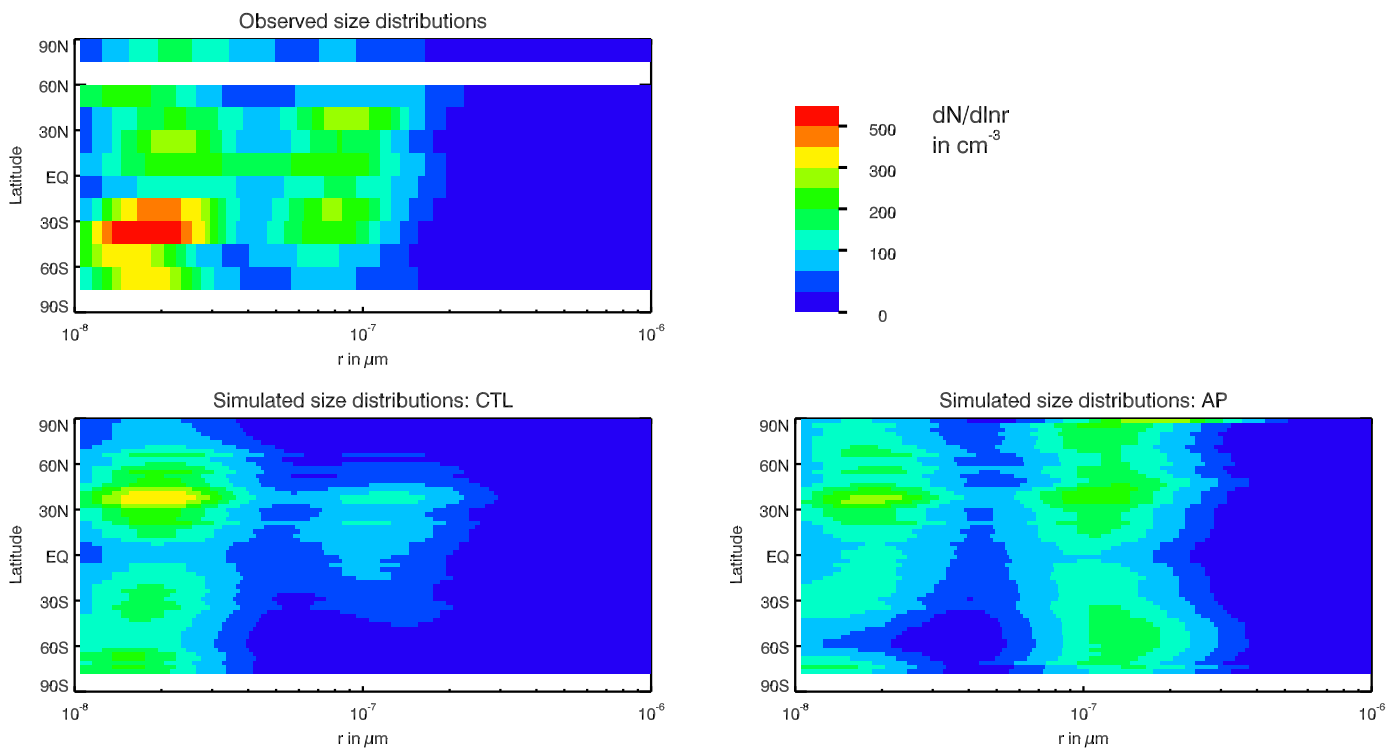

Fig. 8. Size distributions over the oceans, averaged over zonal bands, resulting from the parameters in Fig. 7, from simulations CTL, AP and observations compiled by Heintzenberg et al. (2000). 
but overestimate the measured concentrations at higher latitudes. This points to an underestimation of the scavenging in cold clouds, or to an overestimation of the emissions. Both the Aitken and the accumulation mode zonal mean dry diameters are similar in CTL and AP, but smaller in AP. For the Aitken mode CTL agrees slightly better with the observations on the Southern Hemisphere. The accumulation mode diameter is overestimated up to $100 \%$ by both simulations, especially at higher latitudes. Furthermore, an increase towards the south is simulated, while the observations are relatively constant or decrease slightly. The diameter overestimation is probably due to the size of the emitted sea salt particles in ECHAM5-HAM. The windspeed-dependent mass median radii of accumulation mode sea salt particles ranges between 271 and $284 \mathrm{~nm}$ (Stier et al., 2005; Guelle et al., 2001). Conversion to number mean diameters gives 317 to $332 \mathrm{~nm}$. As sea salt is expected to be the dominant aerosol type in remote ocean regions, the average number mean diameter in the model is probably strongly influenced by this prescribed emitted particle diameter. In the light of the observed diameters (Heintzenberg et al., 2000), which are on average $140 \mathrm{~nm}$ at high Southern latitudes, the emitted particle size might be too large. The possible overestimation of sulfate condensation on accumulation mode particles could also contribute to the too high accumulation mode diameters. Figure 8 illustrates the marine aerosol size distributions and nicely reflects the improvement in the accumulation mode numbers in simulation AP, due to less efficient in-cloud scavenging.

\subsection{AERONET aerosol size distributions}

The Aerosol Robotic Network (AERONET) provides ground-based remote sensing observations of aerosol optical parameters from a large world-wide network of automated sun photometers (Holben et al., 1998). AERONET results from 1993-2003 have been used to derive column mean aerosol size distributions and aerosol volume burdens for 103 stations. The same dataset has been used by Ma and von Salzen (2006) to evaluate simulations of sulfate aerosol size distributions.

The column integrated aerosol volume size distribution $(\mathrm{d} V(d) / \mathrm{d} \ln d)$ has been calculated for simulations CTL and AP as follows, as a function of the particle diameter $d$.

$$
\begin{aligned}
& \frac{\mathrm{d} V(d)}{\mathrm{d} \ln d}= \\
& \sum_{k}\left(\sum_{j=1}^{7} \frac{\pi}{6} d^{3} \frac{N_{j, k}}{\sqrt{2 \pi} \ln \sigma_{j}} \exp \left(-\frac{\left(d-2 r_{\mathrm{wet}, j, k}\right)^{2}}{2 \ln ^{2} \sigma_{j}}\right)\right) \frac{\Delta p_{k}}{g \rho_{\mathrm{air}, k}}
\end{aligned}
$$

The index $k$ runs over all vertical levels. $N_{j, k}$ is the aerosol number concentration of mode $j$ in level $k$, and $r_{\text {wet, } j, k}$ the median aerosol wet radius of mode $j$ in level $k$. The standard deviation $\sigma_{j}$ is fixed to the value of 2.0 for the coarse modes and to 1.59 for all other modes. The vertical integral is weighted with the geometrical layer thicknesses, calculated from the pressure difference $\Delta p_{k}$ between adjacent layer interfaces, the acceleration of gravity $g$ and the air density $\rho_{\text {air }, k}$. As the sun photometers only measure during cloud-free conditions, the simulated data are filtered to include only points with a cloud fraction smaller than $15 \%$ (similar to the analysis by Ma and von Salzen, 2006). The AERONET size distributions are provided for the radius range of $50 \mathrm{~nm}$ to $15 \mu \mathrm{m}$, i.e. the accumulation, coarse and supercoarse modes, while the simulated size distributions are shown for the whole available radius range (nucleation, Aitken, accumulation and coarse modes).

In Fig. 10, the total volume at all analyzed stations (see Fig. 11), integrated over the size distribution, from simulations CTL and AP are compared to the AERONET retrievals. The total vertically integrated aerosol volume correlates poorly between both simulations and the observations. For the low aerosol volume burdens $\left(<0.1 \mu \mathrm{m}^{3} \mu \mathrm{m}^{-2}\right)$ in Fig. 10a, ECHAM5-HAM generally underestimates the volume burden. This is slightly improved in simulation AP. For higher aerosol volume burdens (Fig. 10b), two groups of outliers can be identified. ECHAM5-HAM overestimates the aerosol burden over oceans and underestimates the aerosol burdens mainly over arid regions, both by a factor of 2-10. AERONET measurements may include some cloud contamination from thin uniform cirrus resulting in an overestimation of the aerosol volume burden (Smirnov et al., 2000). The high values over arid regions can possibly be influenced by severe dust events, which are not represented by the model. The biases over oceans and deserts are not significantly improved in simulation AP.

In Fig. 11, the analysis is split into different regions, as mapped in Fig. 9. The simulated size distributions have a higher variance than the AERONET size distributions. The accumulation mode wet diameter is frequently overestimated in both simulations. Simulation AP exhibits lower particle numbers than simulation CTL in the Aitken mode $(d<0.1 \mu \mathrm{m})$, where no observations are available. This is consistent with the lower Aitken mode global number burdens (compare Table 3). In Europe and South America, the size distributions are generally well simulated, but with a significantly too large accumulation mode radius over Europe. Simulation AP exhibits several outliers which do not match the observations at all. At the North American stations, simulation CTL underestimates the coarse mode particle concentration, which is improved in simulation AP (but still too low in the Western US).

The missmatch in the accumulation mode diameter is most severe for the ocean stations. This is consistent with Fig. 7 and the conclusion of Sect. 5.1 that the emitted size of sea salt particles in ECHAM5-HAM might be too large. A second reason for the overestimation of the volume can also be the aerosol water uptake, as here aerosol size distributions at ambient relative humidity are compared. Simulation AP has higher accumulation mode volumes over the oceans than simulation CTL, while the observations lie in-between 


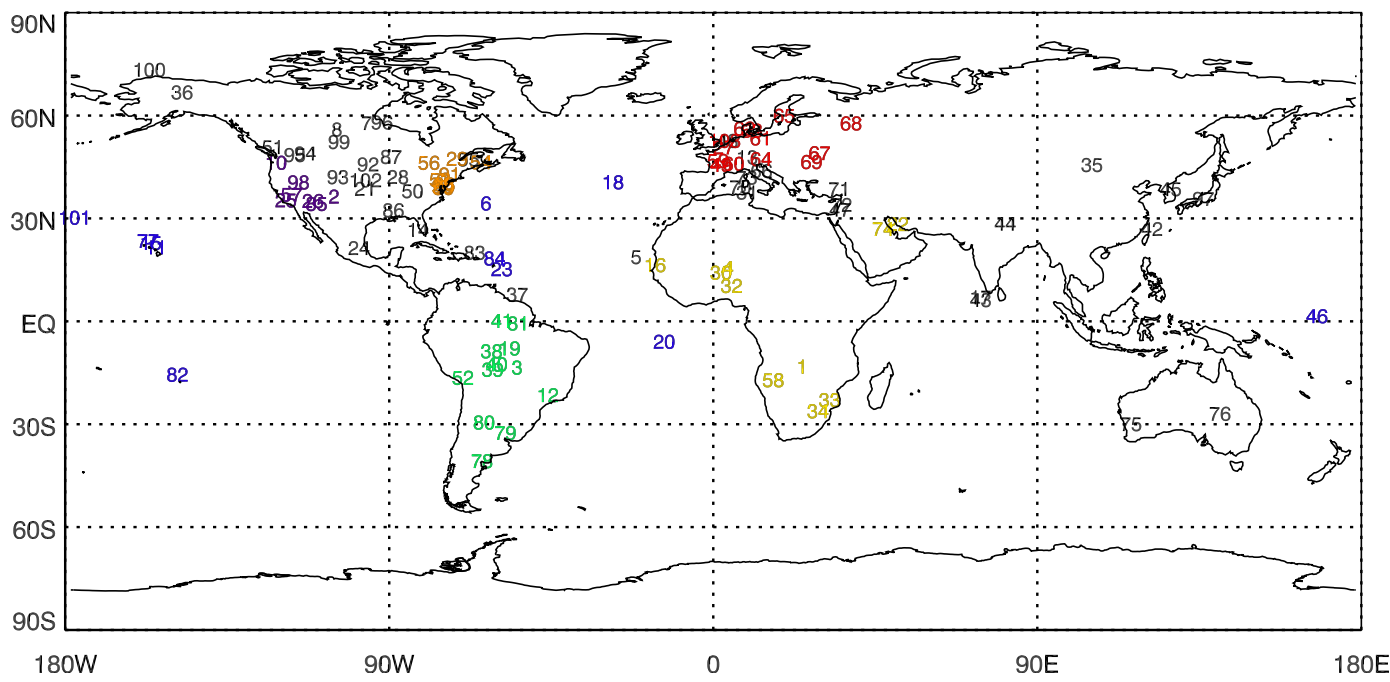

Fig. 9. AERONET stations used for Figs. 10 and 11. Red: Europe, green: South America, violet: Western US, orange: Eastern US, yellow: Africa and Arabia, blue: ocean, black: other stations.

(a) All stations - total volume

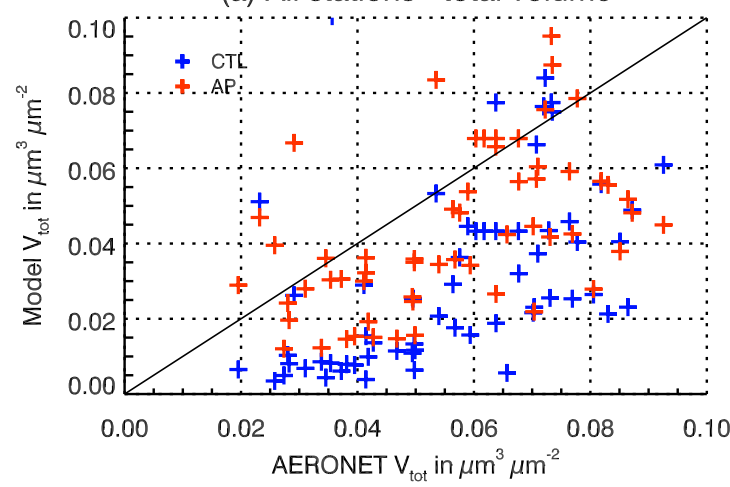

(b) All stations - total volume

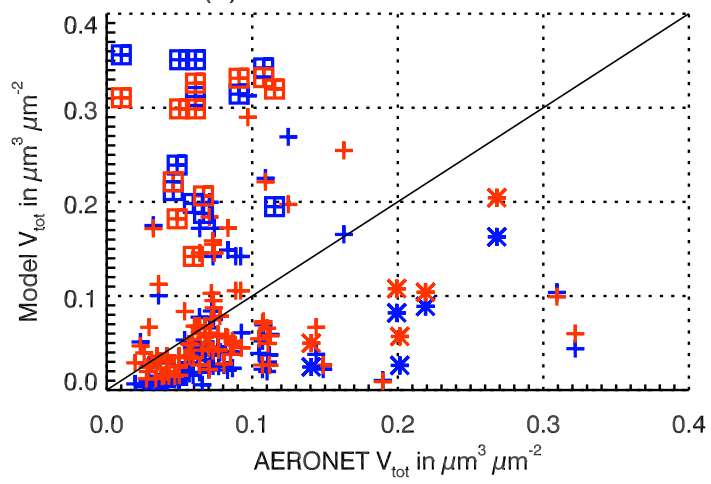

Fig. 10. Aerosol volume burden for all analyzed AERONET stations compared to simulations CTL and AP. Figures (a) and (b) differ only with respect to the axis range. In (b) the ocean stations are marked with a square and stations in arid regions with an asterisk.

both simulations. Over desert areas, ECHAM5-HAM often underestimates both the accumulation mode and the coarse mode volume.

\subsection{Marine boundary layer cloud droplets}

The number of MBL accumulation mode particles changes significantly with the new treatment of in-cloud particles, and this also has a substantial influence on MBL clouds. Droplet number concentrations in marine boundary layer clouds are retrieved from MODIS satellite data by Bennartz (2007). Here the dataset has been extended to 5.25 years and covers nearly the complete ocean region between $60^{\circ} \mathrm{N}$ and $60^{\circ} \mathrm{S}$ on a $1^{\circ} \times 1^{\circ}$ grid. The in-cloud droplet concentration is retrieved on a daily basis. Only gridpoints with more than 10 days with a low cloud fraction higher than $80 \%$ are considered in the analysis. The average over all stratiform liquid cloud cases in the observation period is depicted in Fig. 12.
This figure also displays the in-cloud droplet concentrations $N_{l}$ in simulations CTL and AP as an annual average over the lowest 4 model layers (approximately $900 \mathrm{~m}$ ). Simulation AP yields significantly higher droplet concentrations than simulation CTL all over the globe. Compared to the observations, the pattern of high concentrations along the coasts of North America and east Asia, in the Gulf of Mexico and in the Mediterranean Sea are qualitatively well captured in both simulations. In other near-coast regions the model results and satellite retrievals disagree. The observed enhanced concentrations along the Peruvian and southern African west coasts, which are stratocumulus regions, are lacking in both simulations. On the other hand the droplet concentrations are overestimated in the tropical Atlantic, in the northern Indian ocean and between Australia and Indonesia, where the observations do not show higher than average values. In general the cloud droplet concentration fields are more homogeneous in the model than in the observed data. The 

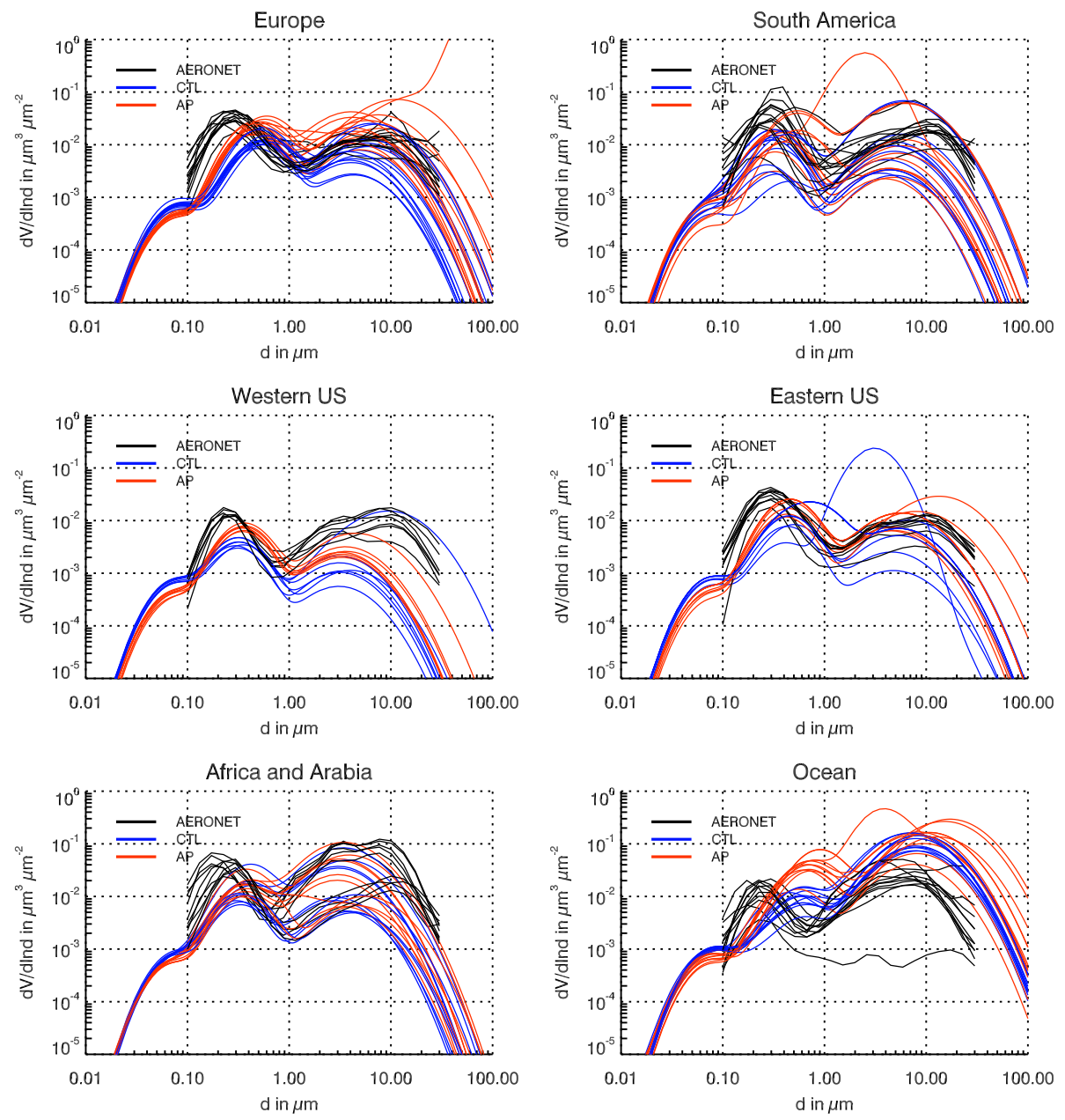

Fig. 11. Vertically integrated size distributions and volume burden for AERONET stations from six different regions, see Fig. 9, compared to simulations CTL and AP.

observations yield minimum values below $25 \mathrm{~cm}^{-3}$ in the remote oceans, suggesting that the minimum droplet concentration of $40 \mathrm{~cm}^{-3}$ in ECHAM5-HAM is too high and should be reconsidered.

A more quantitative comparison to Bennartz's (2007) retrieval is shown in Fig. 13. The values are averaged over five selected off-coast regions, some of them dominated by stratocumulus, and five remote ocean regions with a distance from land of more than $1500 \mathrm{~km}$ (for the regions see Fig. 14). Bennartz (2007) provides two different estimates for all clouds and for clouds with a low likelihood of drizzle. Droplet concentrations are 17-72\% higher for non-drizzling clouds. In ECHAM5-HAM, drizzle is not represented, as cloud droplet which have grown large enough to sediment are assumed to reach the ground within the same timestep. Simulation CTL agrees well with the observations from nondrizzling clouds, but underestimates the droplet number concentrations when comparing the simulations to all clouds. Simulation AP overestimates the droplet number concen- trations by a factor of $1.5-3$, with a slightly better agreement for non-drizzling clouds. This is surprising, because the higher droplet concentrations in simulation AP are the result of higher aerosol number concentrations in the marine boundary layer, especially in the accumulation mode, which agree much better with observations in simulation AP (Sect. 5.1). Furthermore, compared to the retrieval of vertically integrated droplet concentrations by Han et al. (1998), both simulations are significantly too high (Fig. 4d). This suggests either an overestimation of cloud droplet activation or of cloud thicknesses, a too high minimum value for the cloud droplet concentration, or a possible inconsistency between the different observations and retrievals. A more physical cloud droplet activation scheme which accounts for the aerosol particle composition and the so-called competition effect among cloud condensation nuclei (Abdul-Razzak and Ghan, 2000) can possibly lead to lower cloud droplet concentrations. 


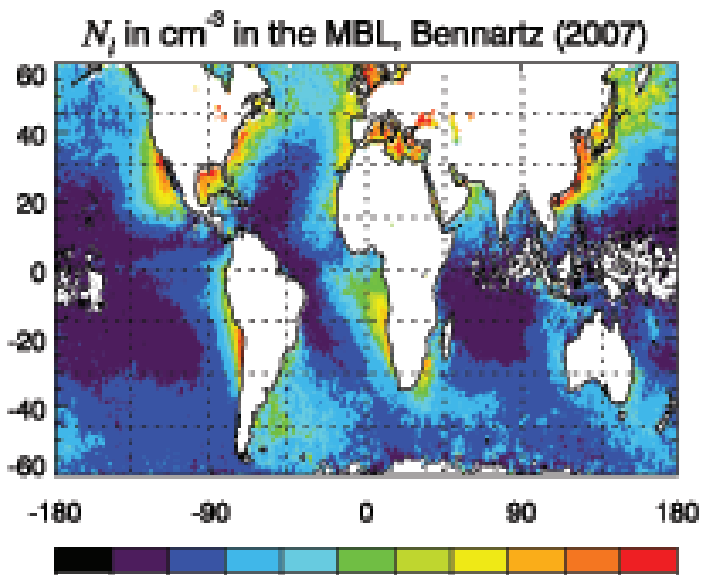

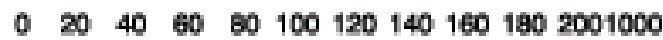
CTL: $N_{l}$ in $\mathrm{cm}^{3}$, below $900 \mathrm{~m}$

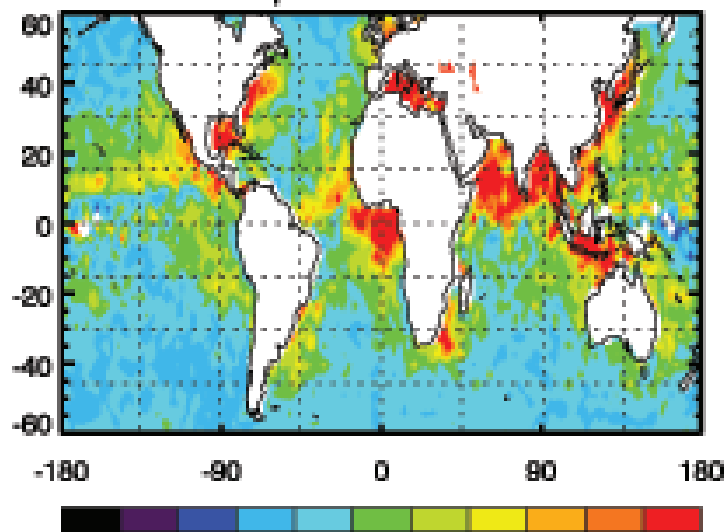

0 20 40 go Ba 100 120 140 160 180 2001000 AP: $N_{l}$ in $\mathrm{cm}^{-3}$, below $900 \mathrm{~m}$

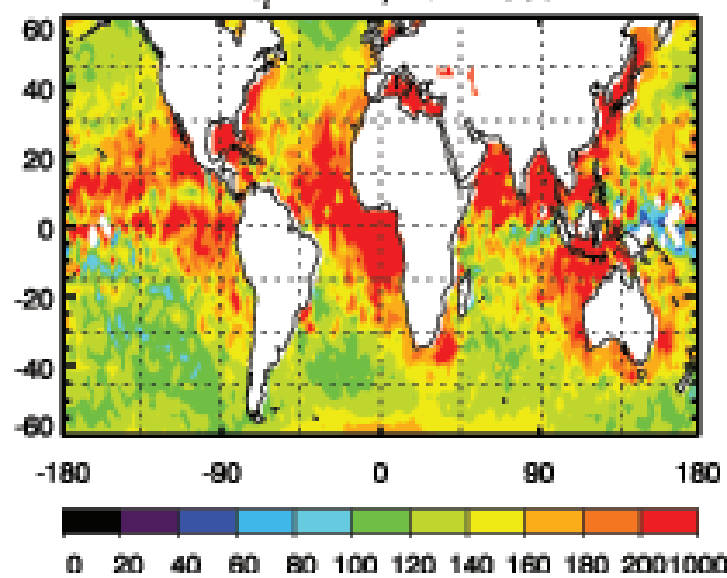

Fig. 12. In-cloud droplet concentrations in marine boundary layer clouds from satellite retrievals by Bennartz (2007) compared to simulations CTL and AP. White: no data.
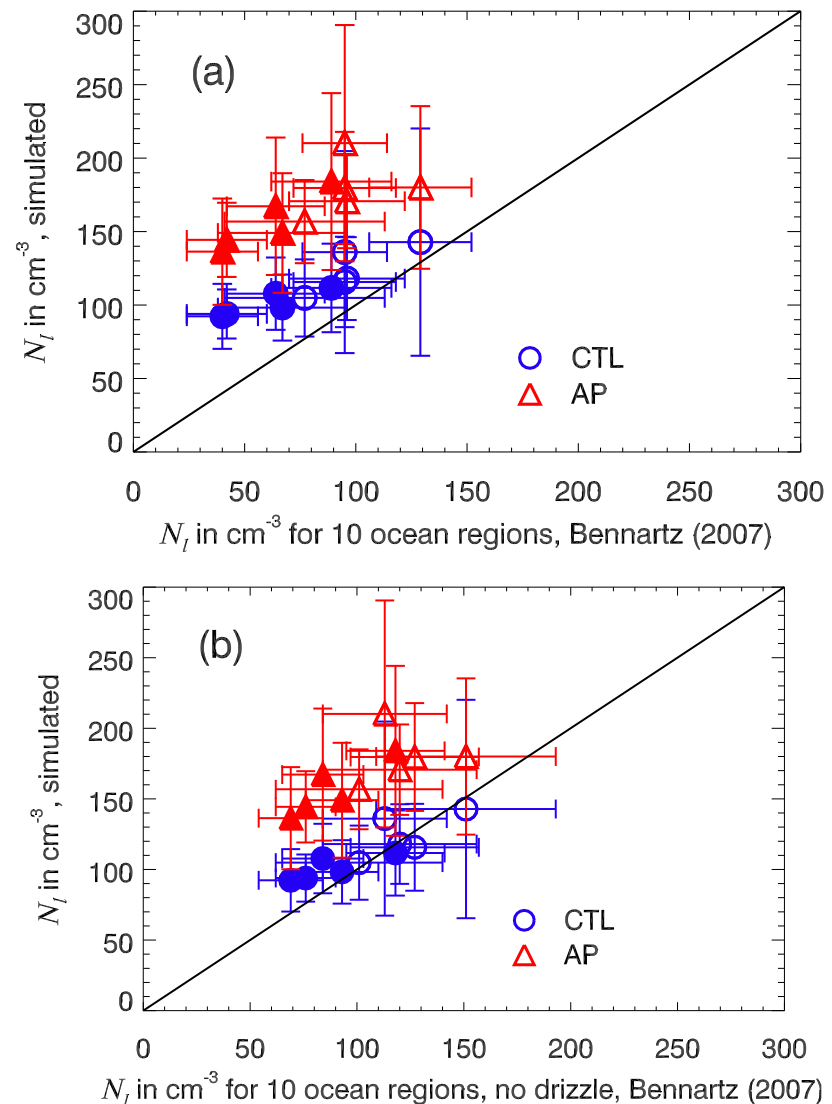

Fig. 13. In-cloud droplet concentrations in marine boundary layer clouds in simulations CTL and AP, compared to retrievals by Bennartz (2007) for the 5 off-coast (open symbols) and 5 remote ocean (filled symbols) regions displayed in Fig. 14. The error bars indicate one standard deviation. (a) includes averages over all clouds, while for (b) the retrievals are for clouds with a low likelihood of drizzle only.

\subsection{Scavenged fraction at Jungfraujoch}

Henning et al. (2004) and Verheggen et al. (2007) have analyzed a large set of observations of interstitial and incloud aerosol in mixed-phase clouds at the high-altitude research site Jungfraujoch (Swiss Alps). Aerosol size distributions were measured by a Scanning Mobility Particle Sizer (SMPS) behind two different inlets, one sampling interstitial aerosol and one sampling total aerosol (interstitial plus residuals from hydrometeors). From these measurements, a "scavenged particle number fraction" can be defined as follows.

$F_{N}=\frac{N_{\text {tot }}(r>50 \mathrm{~nm})-N_{\text {int }}(r>50 \mathrm{~nm})}{N_{\text {tot }}(r>50 \mathrm{~nm})}$

$N_{\text {tot }}$ is the measured total aerosol concentration, and $N_{\text {int }}$ the interstitial aerosol concentration. The cut-off of $50 \mathrm{~nm}$ is chosen because it is the typical dry radius of the smallest activated particles under the orographic conditions of the 


\section{Off-coast regions}

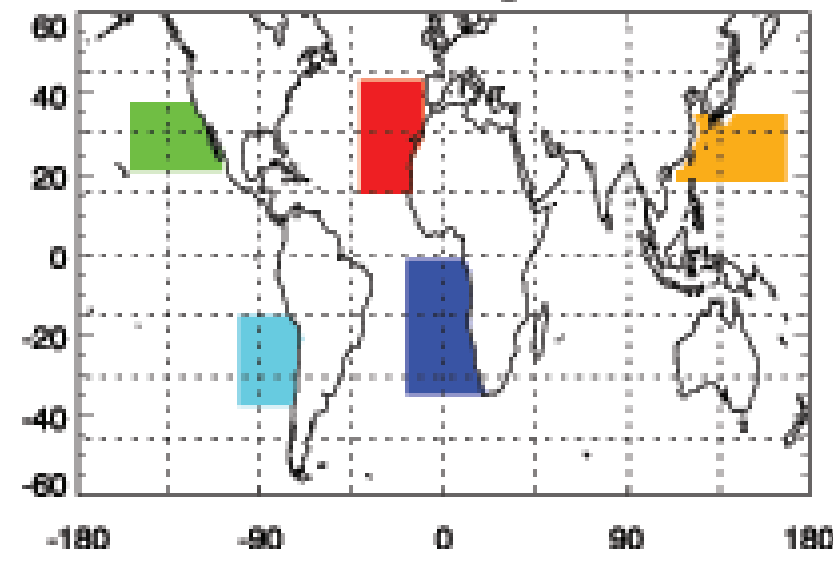

Remote ocean regions

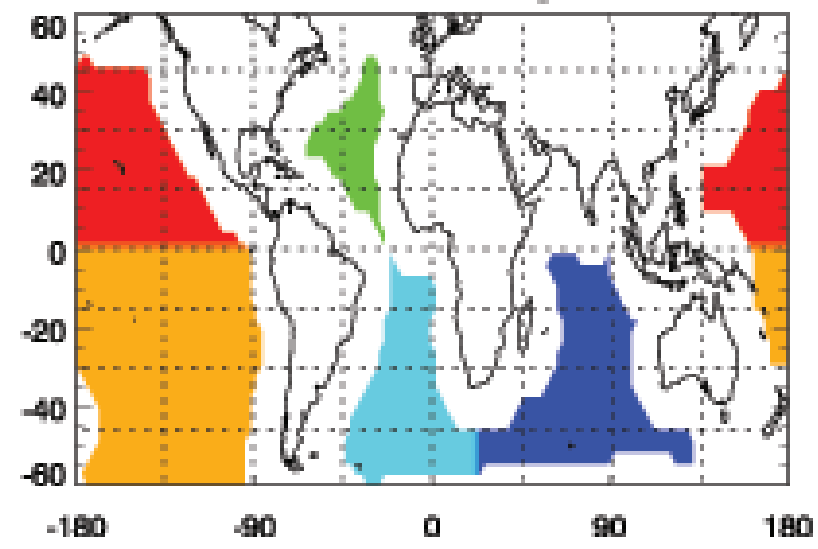

Fig. 14. Regions for which the average values in Fig. 13 are calculated.

Jungfraujoch research station (Baltensperger et al., 1998). The studies by Henning et al. (2004) and Verheggen et al. (2007) have shown that the fraction of scavenged particles decreases with decreasing temperatures in the temperature range $-25^{\circ}$ to $0^{\circ} \mathrm{C}$. The Wegener-Bergeron-Findeisen process is the most likely explanation for this finding. The lower the temperature, the higher is the probability of cloud glaciation and with that the evaporation of cloud droplets, releasing formerly scavenged particles back into the interstitial phase. For temperatures above $-5^{\circ} \mathrm{C}$, Verheggen et al. (2007) found a decrease of the scavenged fraction with increasing total aerosol number. This was explained with a faster depletion of the available water vapor at high cloud condensation nuclei concentrations, leading to a decrease in supersaturation.

In Figs. 15 and 16, the simulations CTL and AP are compared to Verheggen et al.'s (2007) and Henning et al.'s (2004) observations. The model data are sampled over a whole year of instantaneous data which were saved every $12 \mathrm{~h}$, from the four gridpoints which are closest to the Jungfraujoch, throughout the lowest 9 model layers (approximately five (a) CTL: $F_{\mathrm{CTL}, 1}=\left(N_{l}+N_{i}\right) / N_{\mathrm{tot}}(r>50 \mathrm{~nm})$

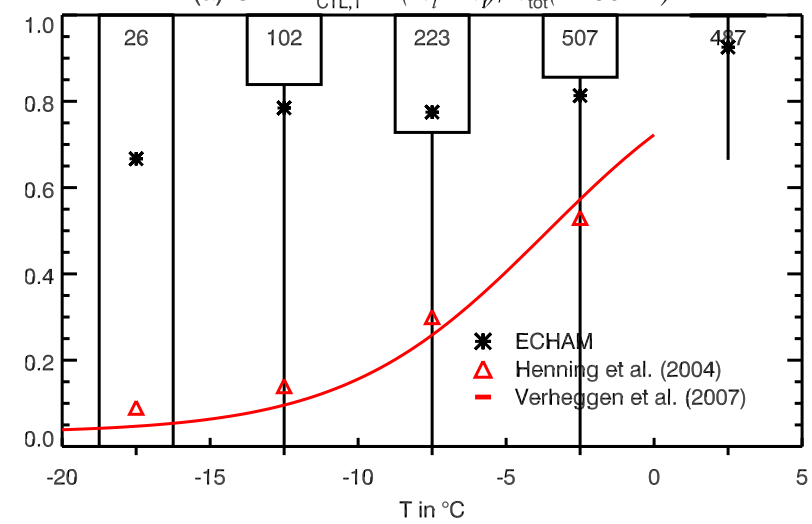

(b) CTL: $F_{\mathrm{CTL}, 2}=R$

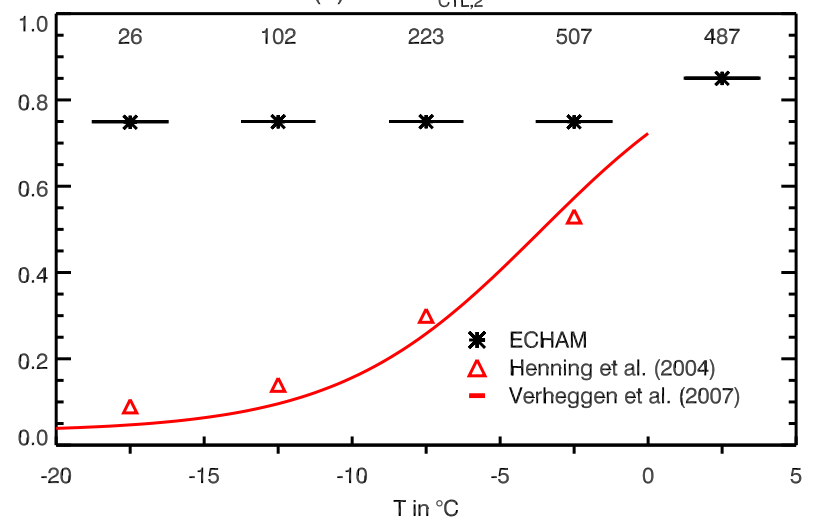

Fig. 15. Scavenged fraction versus temperature for simulation CTL. The scavenged fraction is calculated in two different ways for (a) $F_{\mathrm{CTL}, 1}$ and (b) $F_{\mathrm{CTL}, 2}$, see text. The boxes and whiskers indicate the 10th, 25th, 50th, 75th and 90th percentiles of the simulated values. The mean per temperature interval is marked with an asterisk. The number of data points per temperature interval is given above each box. Observations by Henning et al. (2004) (average values) and Verheggen et al. (2007) (fit through the average values) are included for comparison.

kilometers). This was required in order to obtain a sample which was large enough for the subsequent statistical analyses. Note that the Alpine topography is not well represented on the coarse model grid. The in-cloud values of the cloud droplet concentration $N_{l}$ and the ice crystal concentration $N_{i}$ have been used. For simulation CTL, in total 1345 points were in clouds with temperatures between -20 and $+5^{\circ} \mathrm{C}$, and 1757 data points in simulation AP.

For simulation CTL, the scavenged fraction $F_{N}$ is calculated in two different ways. First, $F_{N}$ is diagnosed from the hydrometeor concentration and the total aerosol number concentration $N_{\text {tot }}(r>50 \mathrm{~nm})=N_{\mathrm{AS}}+N_{\mathrm{CS}}+N_{\mathrm{AI}}+N_{\mathrm{CI}}$, where $N_{j}$ are the number concentrations in the accumulation soluble (AS), coarse soluble (CS), accumulation insoluble (AI) and coarse insoluble (CI) modes. 


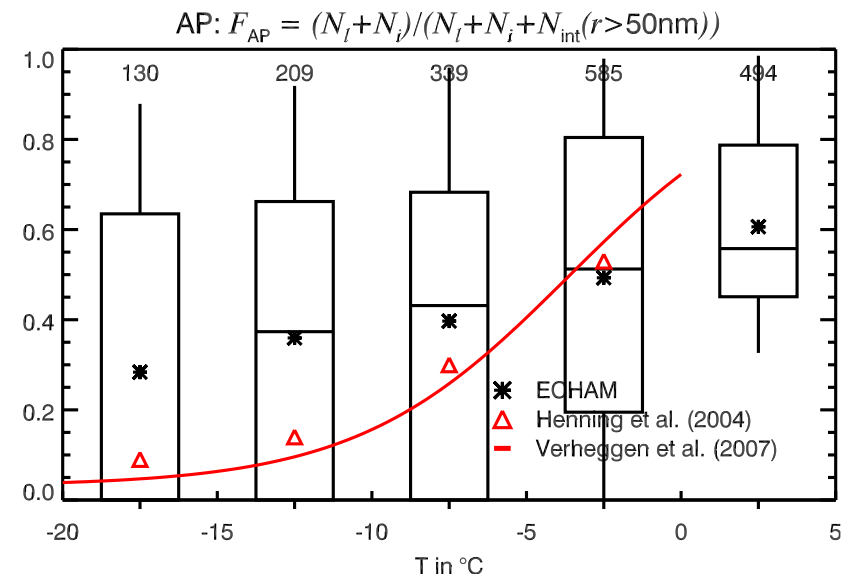

Fig. 16. Scavenged fraction $F_{\text {AP }}$ versus temperature for simulation AP. The boxes and whiskers indicate the 10th, 25th, 50th, 75th and 90th percentiles of the simulated values. The mean per temperature interval is marked with an asterisk. The number of data points per temperature interval is given above each box. Observations by Henning et al. (2004) (average values) and Verheggen et al. (2007) (fit through the average values) are included for comparison.

$F_{\mathrm{CTL}, 1}=\operatorname{Max}\left(1, \frac{N_{l}+N_{i}}{N_{\mathrm{tot}}(r>50 \mathrm{~nm})}\right)$

Calculated in this way, the temperature dependency of $F_{\mathrm{CTL}, 1}$ mainly reflects the temperature dependency of the hydrometeor concentration. We observe a clustering of values of the scavenged fraction at 1 (in liquid clouds, with the droplet concentration equaling or exceeding $N_{\text {tot }}(r>50 \mathrm{~nm})$ ) and, at temperatures below $0^{\circ} \mathrm{C}$, at values below 0.05 (not shown). The low values can be attributed to pure ice clouds, because the minimum droplet concentration in ECHAM5HAM is $40 \mathrm{~cm}^{-3}$ (which would require a total aerosol concentration of $400 \mathrm{~cm}^{-3}$ to give a scavenged fraction of 0.1 , and such high values of $N_{\text {tot }}(r>50 \mathrm{~nm})$ are not observed in the low temperature range). Some data, especially above $-10^{\circ} \mathrm{C}$, also fall in the intermediate range of $0.4 \leq F_{\mathrm{CTL}, 1}<1$. In Fig. 15a these data are binned into temperature intervals of $5^{\circ} \mathrm{C}$ and displayed as boxes, which are limited by the 25 th and 75 th percentiles. The mean, indicated by the asterisks, decreases with temperature from 0.9 to 0.7 , but always overestimates the measured scavenged fraction. The median of the data is 1 over the whole temperature range.

The above investigation is only a diagnostic analysis. Aerosol scavenging in simulation CTL, for the purpose of wet deposition, is calculated with prescribed scavenging coefficients $R_{j}$ (Stier et al., 2005), listed in Table 1. As a second definition of the scavenged fraction in simulation CTL, we calculate the number-weighted mean scavenging coefficient.

$F_{\mathrm{CTL}, 2}=\bar{R}=\sum_{j} \frac{N_{j}}{N_{\mathrm{tot}}(r>50 \mathrm{~nm})} R_{j}(T)$ with $j=\mathrm{AS}, \mathrm{CS}, \mathrm{AI}, \mathrm{CI}$

$F_{\mathrm{CTL}, 2}$ is shown in Fig. 15 b. Virtually all values fall on 0.85 above $0^{\circ} \mathrm{C}$, and on 0.75 below $0^{\circ} \mathrm{C}$. These are the values for the scavenging coefficient for the accumulation soluble mode, which dominates the number concentration of particles larger than $50 \mathrm{~nm}$. The correlation with the observations is therefore poor.

For simulation AP, the scavenged fraction is calculated similar to the measurements.

$F_{\mathrm{AP}}=\frac{N_{l}+N_{i}}{N_{l}+N_{i}+N_{\text {int }}(r>50 \mathrm{~nm})}$

By definition, $F_{\mathrm{AP}}$ is always smaller than 1 in clouds. Similar to $F_{\mathrm{CTL}, 1}$, we observe a clustering of values from pure ice clouds below 0.05, while clouds containing liquid have higher scavenged fractions also in simulation AP. For AP, the values are lower than for CTL, and the median is around 0.5 . As the fraction of liquid clouds decreases with decreasing temperature, the scavenged fraction also exhibits a decreasing trend, similar to but weaker than the observations. The mean scavenged fraction is lower (0.6) than observed at temperatures above $-5^{\circ} \mathrm{C}$ and higher $(0.3)$ than observed at temperatures below $-5^{\circ} \mathrm{C}$.

Verheggen et al. (2007) furthermore report that $F_{N}$ decreases monotonically as a function of the total aerosol number concentration $N_{\text {tot }}(r>50 \mathrm{~nm})$ for $T>-5^{\circ} \mathrm{C}$, but is rather insensitive to $N_{\text {tot }}(r>50 \mathrm{~nm})$ in the mixed-phase clouds below $-5^{\circ} \mathrm{C}$. Above $-5^{\circ} \mathrm{C}$, they find the mean scavenged fraction to decrease from 0.8 for $N_{\text {tot }} \approx 10 \mathrm{~cm}^{-3}$ to 0.3 for $N_{\text {tot }}>800 \mathrm{~cm}^{-3}$, while below $-5^{\circ} \mathrm{C}$, the mean scavenged fraction is approximately 0.1 except at low aerosol concentrations. Verheggen et al.'s (2007) study is based on a very large dataset with over $900 \mathrm{~h}$ of in-cloud measurements. In other observational studies, based on fewer data, this effect is less pronounced. Gillani et al. (1995) find higher scavenged fractions (with a median of 85-90\%) for total aerosol number concentrations up to $600 \mathrm{~cm}^{-3}$ in continental stratiform clouds, and a decrease only for concentrations above this value. Their values are based on measurements of unactivated accumulation mode particles $(0.1-1 \mu \mathrm{m}$ in radius) and cloud droplets. In a previous campaign at the Jungfraujoch, no dependence of the activated fraction on the aerosol particle concentration was found (Baltensperger et al., 1998), and the average activated fraction for $r>50 \mathrm{~nm}$ from four events during a campaign in October/November 1993 was 0.48.

The dependency of $F_{N}$ on the total aerosol concentration has been analyzed for simulations CTL and AP in Figs. 17 and 18. Only the definition $F_{\mathrm{CTL}, 1}$ Eq. (7) for the scavenged fraction in simulation CTL is shown here, as $F_{\mathrm{CTL}, 2}$ is not sensitive to the total particle number. In Figs. 17a, b and $18 \mathrm{a}, \mathrm{b}$, we distinguish between clouds containing liquid droplets and pure ice clouds. As the minimum cloud droplet number concentration in ECHAM5 is prescribed to $40 \mathrm{~cm}^{-3}$, the scavenged fraction in liquid and mixed-phase 
(a) CTL: $F_{\mathrm{CTL}, 1}=\left(N_{l}+N_{i}\right) / N_{\mathrm{tot}}(r>50 \mathrm{~nm})$

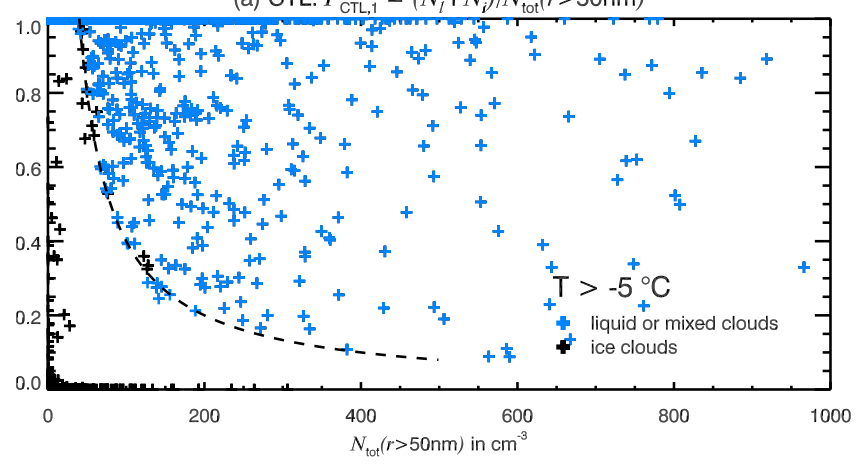

(c) CTL: $F_{\mathrm{CTL}, 1}=\left(N_{l}+N_{i}\right) / N_{\mathrm{tot}}(r>50 \mathrm{~nm})$

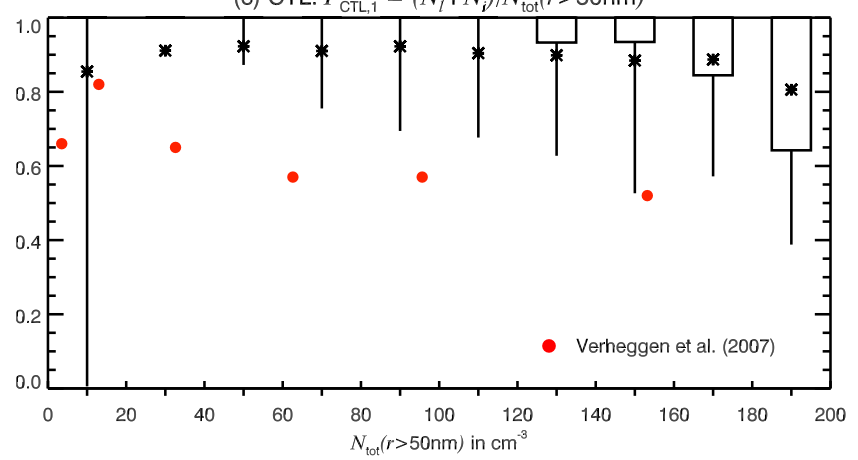

(b) CTL: $F_{\mathrm{CTL}, 1}=\left(N_{l}+N_{i}\right) / N_{\mathrm{tot}}(r>50 \mathrm{~nm})$

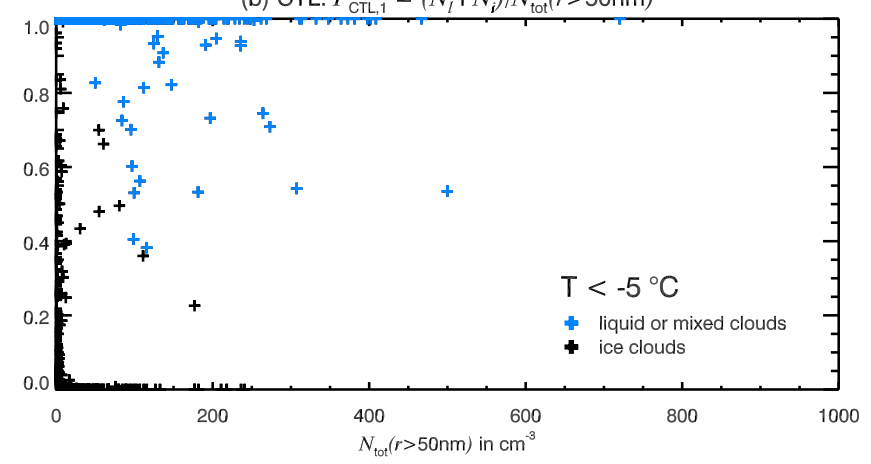

(d) CTL: $F_{\mathrm{CTL}, 1}=\left(N_{t}+N_{i}\right) / N_{\mathrm{tot}}(r>50 \mathrm{~nm})$

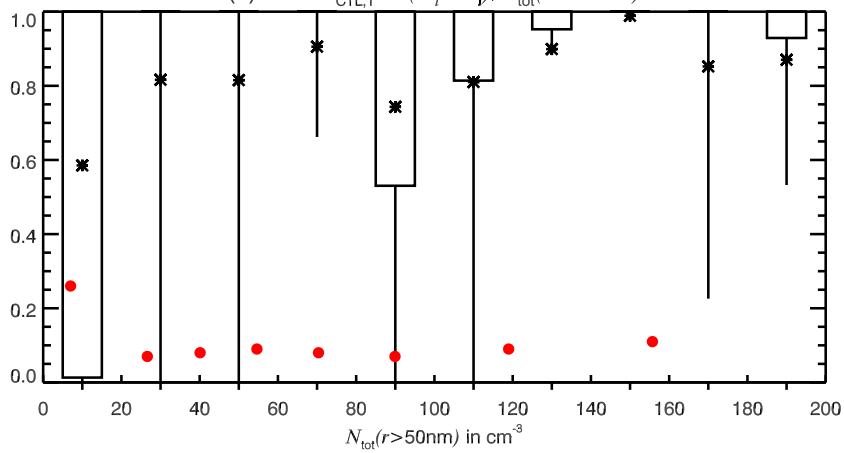

Fig. 17. Scavenged fraction $F_{\mathrm{CTL}, 1}$ versus aerosol concentration for simulation CTL, for temperatures above (a and $\left.\mathbf{c}\right)$ and below (b and $\left.\mathbf{d}\right)$ $-5^{\circ} \mathrm{C}$. The dashed line gives the scavenged fraction for the minimum droplet concentration of $40 \mathrm{~cm}^{-3}$. The boxplots (c) and (d) are based on the same data as the plots above, but are displayed only for $N_{\text {tot }}(r>50 \mathrm{~nm}) \leq 200 \mathrm{~cm}^{-3}$. The boxes and whiskers indicate the 10 th, $25 \mathrm{th}$, 50th, 75th and 90th percentiles. The mean per concentration interval is marked with an asterisk. Observations by Verheggen et al. (2007) (average values) are included for comparison.

clouds is constrained in the range of low aerosol concentrations. For simulation CTL, it is 1 if $N_{\text {aer,total }}>50 \mathrm{~nm}$ is below $40 \mathrm{~cm}^{-3}$, and is enveloped by a function of the form $1 / x$ above this threshold (compare to Eq. (7) for large ratios of total aerosol to hydrometeors). For simulation AP, values of $\left(N_{l}+N_{i}+N_{\text {int }}(r>50 \mathrm{~nm})\right)$ below $40 \mathrm{~cm}^{-3}$ occur only in ice clouds. Above $40 \mathrm{~cm}^{-3}$ the scavenged fraction for liquid/mixed clouds is enveloped by a function of the form $1 /(1+x)$ (compare to Eq. 9). In general, pure ice clouds have low values of $F_{N}$ in both simulations except at total aerosol concentrations below $20 \mathrm{~cm}^{-3}$. Liquid clouds often exhibit the maximum scavenged fraction of 1 in simulation CTL, but tend to spread broadly between the minimum envelope and 1 in simulation AP. As not enough data were available for higher total aerosol concentrations, the 10th, 25th, 50th, 75th and 90th percentiles and the median for $\mathrm{x}$-axis-intervals of $20 \mathrm{~cm}^{-3}$ are limited to $N_{\text {tot }}(r>50 \mathrm{~nm})$ and $\left(N_{l}+N_{i}+N_{\text {int }}(r>50 \mathrm{~nm})\right)$, respectively, below $200 \mathrm{~cm}^{-3}$. Verheggen et al.'s (2007) data for this range are also included in Figs. 17c, d and 18c, d.
Simulation CTL overestimates $F_{N}$ for both $T>-5^{\circ} \mathrm{C}$ and $T<-5^{\circ} \mathrm{C}$. For the higher temperature range, the mean scavenged fraction is overestimated by approximately $40 \%$ and decreases slightly with increasing aerosol number concentration. For the lower temperature range, the spread is very broad due to the (relatively few) remaining liquid clouds with high values of $F_{N}$, and no trend is found. In simulation $\mathrm{AP}, F_{N}$ is underestimated for $T>-5^{\circ} \mathrm{C}$ for $\left(N_{l}+N_{i}+N_{\text {int }}(r>50 \mathrm{~nm})\right)$ below $40 \mathrm{~cm}^{-3}$, because these values only include ice clouds. Above $40 \mathrm{~cm}^{-3}$, the mean of the scavenged fraction is approximately $20 \%$ higher than the measurements, but exhibits a similar slightly decreasing trend. For $T<-5^{\circ} \mathrm{C}, F_{N}$ is overestimated in intervals which include many liquid/mixed-phase clouds, but is not as high as in simulation CTL. Possible reasons for the overestimation of the scavenged fraction in simulation AP can be a too high occurrence of supercooled liquid clouds at these temperatures in the model, or an overestimation of ice particle concentrations. 
(a) AP: $F_{\mathrm{AP}}=\left(N_{l}+N_{i}\right) /\left(N_{l}+N_{i}+N_{\text {int }}(r>50 \mathrm{~nm})\right)$

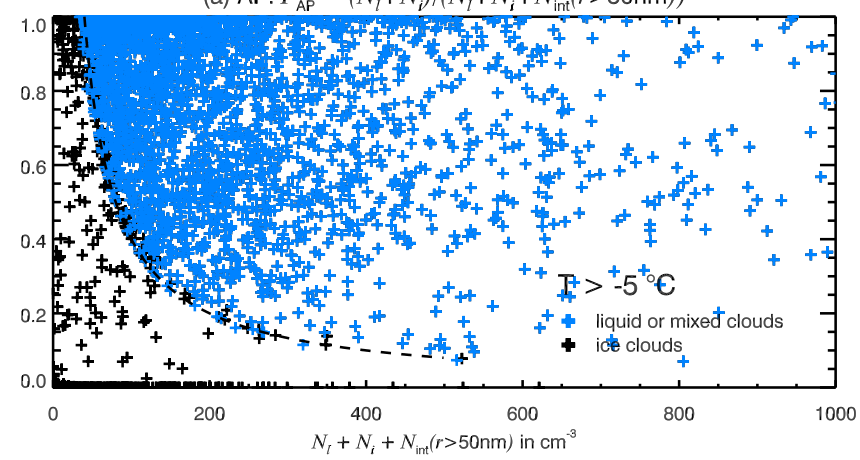

(c) AP: $F_{\text {AP }}=\left(N_{t}+N_{i}\right) /\left(N_{l}+N_{i}+N_{\text {int }}(r>50 \mathrm{~nm})\right)$

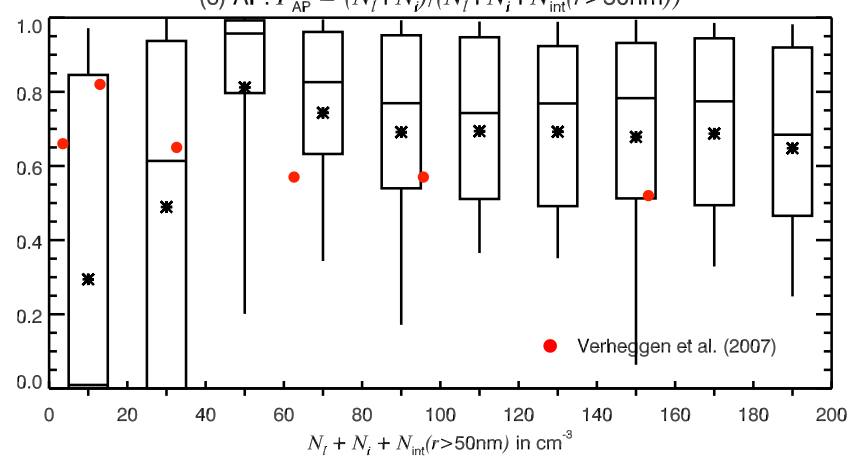

Fig. 18. As Fig. 17, but for simulation AP.

\section{Sensitivity studies}

Although the correlation of several simulated aerosol parameters (marine aerosol number concentrations, aerosol volume burdens in some locations, the aerosol scavenged fraction) with observations has improved by the introduction of an explicit treatment of aerosol processing in clouds, two global parameters are in significant disagreement with observations: the aerosol optical depth and the droplet number burden. In several sensitivity studies, it has been explored which processes can improve the correlation with observations in this respect. The simulations AP-bcs, AP-aod, AP-coll and APcomb are listed in Table 2. Simulation AP-comb, which combines all three sensitivity tests, is additionally included in Fig. 4.

The revised below-cloud scavenging scheme by Croft et al. (2008a) decreases the global mean aerosol optical depth by $15 \%$ to 0.34 , but has no clear influence on the droplet burden, probably because only the near-surface layers are affected. Similarly, the reduced water uptake on sea salt particles (AP-aod) reduces the aerosol optical depth by $20 \%$ to 0.32. In this simulation, the slight increase in droplet burden can be explained by the reduced sedimentation of sea salt particles. Simulation AP-coll, with enhanced collision scavenging for accumulation and coarse modes, strongly reduces the concentration of particles which are available for (b) AP: $F_{\mathrm{AP}}=\left(N_{l}+N_{i}\right) /\left(N_{l}+N_{i}+N_{\text {int }}(r>50 \mathrm{~nm})\right)$

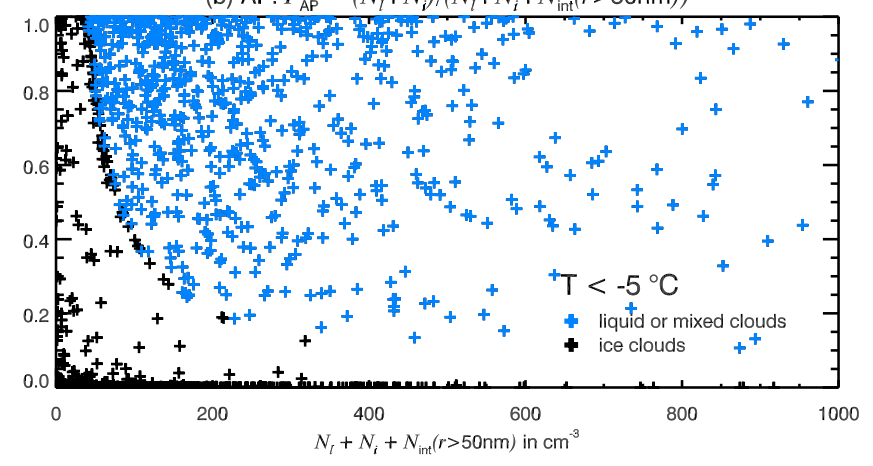

(d) AP: $F_{\mathrm{AP}}=\left(N_{l}+N_{i}\right) /\left(N_{l}+N_{i}+N_{\mathrm{int}}(r>50 \mathrm{~nm})\right)$

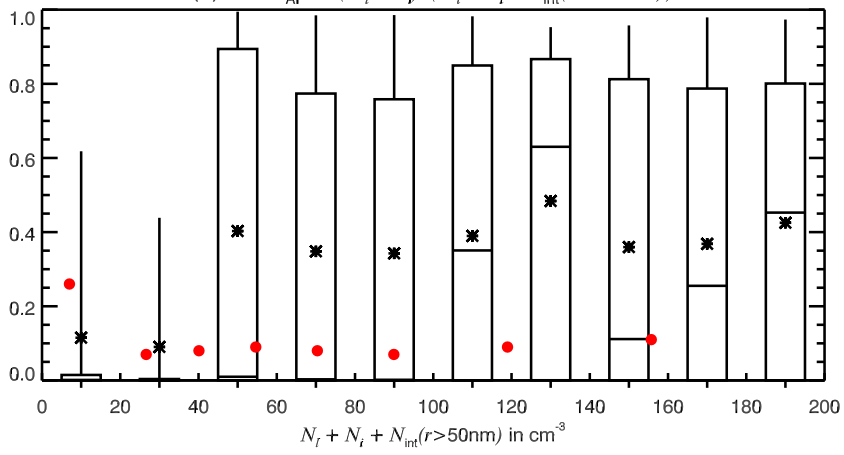

droplet activation. Therefore the droplet concentrations are decreased and wet deposition is increased. After readjustment of the radiation balance, the aerosol optical depth is reduced by $28 \%$ to 0.29 and the in-cloud droplet burden $N_{l, \text { cloudy }}^{\mathrm{B}}$ by $22 \%$ to $7.6 \times 10^{10} \mathrm{~m}^{-2}$. In the combined simulation AP-comb, $N_{l, \text { cloudy }}^{\mathrm{B}}=8.0 \times 10^{10} \mathrm{~m}^{-2}$ and $\mathrm{AOD}=0.22$ is reached. As seen in Fig. 4, this is still higher than the observations, but similar to simulation CTL with standard ECHAM5-HAM. Therefore, a further reduction can be mainly be expected from changes in the aerosol emissions, especially in the sea salt emissions. The hypothesis of overestimated sea salt emissions is corroborated by the overprediction of aerosol optical depth in the Southern Hemisphere.

\section{Conclusions}

An explicit treatment of in-cloud aerosol particles in the global aerosol-climate model ECHAM5-HAM has allowed a global assessment of the turnover of aerosol particles in stratiform clouds. Compared to previous estimates (Pruppacher and Jaenicke, 1995), ECHAM5-HAM simulates a lower number of cycles through clouds ( 0.5 compared to 3 ). The discrepancy is due to the fact that aerosol processing in convective clouds is not yet included in ECHAM5-HAM, and to an overestimation of the global liquid water path by 
Pruppacher and Jaenicke (1995). Recalculating Pruppacher and Jaenicke's (1995) estimate for stratiform clouds yields 0.4 cycles through clouds, which is in good agreement with ECHAM5-HAM. It has become obvious that aerosol cycling through convective clouds contributes significantly to global aerosol processing, and an extension of the model in this direction is desirable. This will in future be possible with the double-moment scheme for convective clouds by Lohmann (2008). Furthermore, as below-cloud evaporation contributes significantly to the release of aerosol mass from hydrometeors, a better treatment of this process is necessary. A prognostic double-moment formulation for rain (recently implemented by Posselt and Lohmann, 2008) is necessary to accurately calculate the size of aerosol particles released in dry layers below clouds.

The rates of aerosol mass transfer into cloud droplets and ice crystals can be analyzed. Nucleation scavenging dominates over collision scavenging for sulfate, sea salt and mineral dust, while the two processes are of similar importance for black carbon and organic carbon. Aqueous-phase formation of sulfate is the most important source of atmospheric sulfate particles. In the simulation with explicit aerosol processing (AP) fewer particles are scavenged into the cloud phase than in the control simulation CTL. Therefore more particles are available for activation, resulting in higher incloud droplet concentrations. An enhancement of the autoconversion rate is necessary in order to achieve an equilibrated radiation balance, and this in turn reduces the liquid water path.

Comparison to different observations reveals several inconsistencies. While the marine boundary layer accumulation mode number concentrations are better reproduced in simulation AP than in simulation CTL, the opposite is true for the droplet concentrations in marine boundary layer clouds. This can be due to overestimated sea salt emissions or to the treatment of cloud droplet activation in the model.

The wet and dry diameter of the accumulation mode is overestimated especially over oceans. Total volume burden at a large number of AERONET stations is not well simulated, with an overestimation over the oceans and an underestimation in desert areas. At stations with a lower aerosol volume burden, simulation AP slightly improves the correlation to measurements. The scavenged particle number fraction at the Jungfraujoch is better simulated in simulation AP than in CTL. CTL generally overestimates the scavenged fraction. While for CTL this is analyzed only diagnostically and the scavenged fraction for wet deposition is fixed to excessively high values at low temperatures, the scavenged fraction in AP is actually directly applied for wet deposition calculations.

While the aerosol optical thickness is strongly overestimated in simulation AP due to reduced wet deposition of aerosol particles, it has been shown in sensitivity studies that this can be improved by a more physical and more detailed below-cloud scavenging scheme, reduced water uptake on sea salt aerosols or enhanced collision scavenging of large particles. Further improvements can mainly be expected from changes in the sea salt emission function in ECHAM5-HAM, or from a more physical cloud droplet activation scheme.

Acknowledgements. The authors thank Sylvaine Ferrachat, Bernd Kärcher, Geert-Jan Roelofs, Philip Stier and two anonymous reviewers for helpful comments and discussions, and Stefan Kinne, Bart Verheggen and Ernest Weingartner for providing data. We thank the AERONET Principal Investigators and their staff for establishing and maintaining the 103 sites used in this investigation. This study was conducted within the Swiss climate research program NCCR Climate.

Edited by: J. Seinfeld

\section{References}

Abdul-Razzak, H. and Ghan, S. J.: A parameterization of aerosol activation 2. Multiple aerosol types, J. Geophys. Res., 105, 6837-6844, 2000.

Adler, R., Huffman, G., Chang, A., Ferraro, R., Xie, P., Janowiak, J., Rudolf, B., Schneider, U., Curtis, S., Bolvin, D., Gruber, A., Susskind, J., Arkin, P., and Nelkin, E.: The version-2 global precipitation climatology project (GPCP) monthly precipitation analysis (1979-present), J. Hydrometeorol., 4, 1147-1167, 2003.

Baltensperger, U., Schwikowski, M., Jost, D. T., Nyeki, S., Gäggeler, H. W., and Poulida, O.: Scavenging of atmospheric constituents in mixed phase clouds at the high-alpine site Jungfraujoch Part I: Basic concept and aerosol scavenging by clouds, Atmos. Environ., 32, 3975-3983, 1998.

Barth, M. C., Rasch, P. J., Kiehl, J. T., Benkovitz, C. M., and Schwartz, S. E.: Sulfur chemistry in the National Center for Atmospheric Research Community Climate Model: Description, evaluation, features, and sensitivity to aqueous chemistry, J. Geophys. Res., 105, 1387-1416, 2000.

Beheng, K. D.: A parameterization of warm cloud microphysical conversion processes, Atmos. Res., 33, 193-206, 1994.

Bennartz, R.: Global assessment of marine boundary layer cloud droplet number concentration from satellite, J. Geophys. Res., 112, D02201, doi:10.1029/2006JD007547, 2007.

Bower, K., Choularton, T., Gallagher, M., Colvile, R., Wells, M., Beswick, K., Wiedensohler, A., Hansson, H., Svenningsson, B., Swietlicki, E., Wendisch, M., Berner, A., Kruisz, C., Laj, P., Facchini, M., Fuzzi, S., Bizjak, M., Dollard, G., Jones, B., Acker, K., Wieprecht, W., Preiss, M., Sutton, M., Hargreaves, K., StoretonWest, R., Cape, J., and Arends, B.: Observations and modelling of the processing of aerosol by a hill cap cloud, Atmos. Environ., 31, 2527-2543, 1997.

Croft, B., Lohmann, U., Stier, P., Wurzler, S., Martin, R. V., Feichter, J., and Ferrachat, S.: Aerosol Size-Dependent BelowCloud Scavenging by Rain and Snow in the ECHAM5-HAM GCM, in preparation, 2008a.

Croft, B., Lohmann, U., Martin, R. V., Stier, P., Wurzler, S., Feichter, J., Heikkilä, U., and Ferrachat, S.: Microphysicallydependent in-cloud scavenging in warm, mixed and ice clouds in the Global Climate Model ECHAM5-HAM, in preparation, 2008 b. 
Easter, R. C., Ghan, S. J., Zhang, Y., Saylor, R. D., Chapman, E. G., Laulainen, N. S., Abdul-Razzak, H., Leung, L. R., Bian, X., and Zaveri, R. A.: MIRAGE: Model description and evaluation of aerosols and trace gases, J. Geophys. Res., 109, D20210, doi:10.1029/2004JD004571, 2004.

Flossmann, A., Hall, W. D., and Pruppacher, H.: A Theoretical Study of the Wet Removal of Atmospheric Pollutants. Part I: The redistribution of aerosol-particles captured through nucleation and impaction scavenging by growing cloud drops, J. Atmos. Sci., 42, 583-606, 1985.

Ghan, S. J., Chuang, C. C., and Penner, J. E.: A parameterization of cloud droplet nucleation part I: single aerosol type, Atmos. Res., 30, 198-221, 1993.

Ghan, S. J. and Schwartz, S. E.: Aerosol properties and processes: A path from field and laboratory measurements to global climate models, B. Am. Meteorolog. Soc., 88, 1057-1083, 1993.

Gillani, N. V., Schwartz, S. E., Leaitch, W. R., Strapp, J. W., and Isaac, G. A.: Field observations in continental stratiform clouds: Partitioning of cloud particles between droplets and unactivated interstitial aerosols, J. Geophys. Res., 100, 18 687-18 706, 1995.

Greenwald, T. J., Stephens, G. L., Vonder Haar, T. H., and Jackson, D. L.: A physical retrieval of cloud liquid water over the global oceans using Special Sensor Microwave/Imager (SSM/I) observations, J. Geophys. Res., 98, 18 471-18 488, 1993.

Guelle, W., Schulz, M., Balkanski, Y., and Dentener, F.: Influence of the source formulation on modeling the atmospheric global distribution of sea salt aerosol, J. Geophys. Res., 106, 27509 27 524, 2001.

Han, Q., Rossow, W. B., Chou, J., and Welch, R. M.: Global variation of column droplet concentration in low-level clouds, Geophys. Res. Lett., 25, 1419-1422, 1998.

Heintzenberg, J., Covert, D. C., and van Dingenen, R.: Size distributions and chemical composition of marine aerosols: a compilation and review, Tellus, 52B, 1104-1122, 2000.

Henning, S., Bojinski, S., Diehl, K., Ghan, S., Nyeki, S., Weingartner, E., Wurzler, S., and Baltensperger, U.: Aerosol partitioning in natural mixed-phase clouds, Geophys. Res. Lett., 31, L06101, doi:10.1029/2003GL019025, 2004.

Holben, B., Eck, T., Slutsker, I., Tanré, D., Buis, J., Setzer, A., Vermote, E., Reagan, J., Kaufman, Y. J., Nakajima, T., Lavenu, F., Jankowiak, I., and Smirnov, A.: AERONET - A Federated Instrument Network and Data Archive for Aerosol Characterization, Remote Sens. Environ., 66, 1-16, 1998.

Hoose, C., Lohmann, U., Stier, P., Verheggen, B., and Weingartner, E.: Aerosol Processing in Mixed-Phase Clouds in ECHAM5HAM: Model Description and Comparison to Observations, J. Geophys. Res., 113, D07210, doi:10.1029/2007JD009251, 2008.

Hoppel, W. A., Frick, G. M., and Larson, R. E.: Effect of nonprecipitating clouds on the aerosol size distribution in the marine boundary layer, Geophys. Res. Lett., 13, 125-128, 1986.

Hoppel, W. A., Fitzgerald, J., W., Frick, G. M., Larson, R. E., and Mack, E. J.: Aerosol Size distributions and optical properties found in the marine boundary layer over the Atlantic Ocean, J. Geophys. Res., 95, 3659-3686, 1990.

Ivanova, I. T. and Leighton, H. G.: Aerosol-cloud interactions in a mesoscale model. Part I: Sensitivity to activation and collisioncoalescence, J. Atmos. Sci., 65, 289-308, 2008.

Jones, A., Roberts, D. L., Woodage, M. J., and Johnson, C. E.: Indirect sulphate aerosol forcing in a climate model with an interac- tive sulphur cycle, J. Geophys. Res., 106, 20 293-20 310, 2001.

Kärcher, B. and Lohmann, U.: A parameterization of cirrus cloud formation: Homogeneous freezing including effects of aerosol size, J. Geophys. Res., 107(D23), 4698, doi:10.1029/2001JD001429, 2002.

Khairoutdinov, M. and Kogan, Y.: A New Cloud Physics Parameterization in a Large-Eddy Simulation Model of Marine Stratocumulus, Mon. Weather Rev., 128, 229-243, 2000.

Kiehl, J. T. and Trenberth, K.: Earth's annual global mean energy budget, Bull. Amer. Meteorol. Soc., 78, 197-208, 1997.

Kinne, S.: Remote sensing data combinations - superior global maps for aerosol optical depth, in: Satellite Aerosol Remote Sensing Over Land, edited by: Kokhanovsky, A. A. and De Leeuw, G., Springer, in press, 2008.

Koch, D., Schmidt, G. A., and Field, C. V.: Sulfur, sea salt, and radionuclide aerosols in GISS ModelE, J. Geophys. Res., 111, D06206, doi:10.1029/2004JD005550, 2006.

Lelieveld, J., Crutzen, P. J., and Rodhe, H.: Zonal average cloud characteristics for global atmospheric chemistry modelling, Tech. Rep. CM 76, MISU, Department of Meteorology, Stockholm University, Stockholm, 54 pp., 1989.

Lin, B. and Rossow, W. B.: Seasonal variation of liquid and ice water path in nonprecipitating clouds over oceans, J. Climate, 9, 2890-2902, 1996.

Lin, H. and Leaitch, R.: Development of an in-cloud aerosol activation parameterization for climate modelling, in: Proc. WMO Workshop on Measurements of Cloud Properties for Forecasts of Weather, Air Quality and Climate, Mexico City, 1997.

Lohmann, U.: Global anthropogenic aerosol effects on convective clouds in ECHAM5-HAM, Atmos. Chem. Phys., 8, 2115-2131, 2008 ,

http://www.atmos-chem-phys.net/8/2115/2008/.

Lohmann, U. and Roeckner, E.: Design and performance of a new cloud microphysics scheme developed for the ECHAM general circulation model, Clim. Dynam., 12, 557-572, 1996.

Lohmann, U., Feichter, J., Chuang, C. C., and Penner, J. E.: Prediction of the number of cloud droplets in the ECHAM GCM, J. Geophys. Res., 104, 9169-9198, 1999.

Lohmann, U., Stier, P., Hoose, C., Ferrachat, S., Kloster, S., Roeckner, E., and Zhang, J.: Cloud microphysics and aerosol indirect effects in the global climate model ECHAM5-HAM, Atmos. Chem. Phys., 7, 3425-3446, 2007,

http://www.atmos-chem-phys.net/7/3425/2007/.

Ma, X. and von Salzen, K.: Dynamics of the sulphate aerosol size distribution on a global scale, J. Geophys. Res., 111, D08206, doi:10.1029/2005JD006620, 2006.

O’Dell, C. W., Wentz, F., and Bennartz, R.: Cloud Liquid Water Path from Satellite-Based Passive Microwave Observations: A New Climatology over the Global Oceans, J. Climate, 21, 17211739, 2008.

Posselt, R. and Lohmann, U.: Introduction of prognostic rain in ECHAM5: design and single column model simulations, Atmos. Chem. Phys., 8, 2949-2963, 2008,

http://www.atmos-chem-phys.net/8/2949/2008/.

Pruppacher, H. R. and Jaenicke, R.: The processing of water vapor and aerosols by atmospheric clouds, a global estimate, Atmos. Res., 38, 283-295, 1995.

Pruppacher, H. R. and Klett, J. D.: Microphysics of Clouds and Precipitation, Atmospheric and Oceanographic Sciences Li- 
brary, Kluwer Academic Publishers, Dordrecht, The Netherlands, 1997.

Roelofs, G. J., Stier, P., Feichter, J., Vignati, E., and Wilson, J.: Aerosol activation and cloud processing in the global aerosolclimate model ECHAM5-HAM, Atmos. Chem. Phys., 6, 23892399, 2006,

http://www.atmos-chem-phys.net/6/2389/2006/.

Smirnov, A., Holben, B. N., Eck, T. F., Dubovik, O., and Slutsker, I.: Cloud-Screening and Quality Control Algorithms for the AERONET Database, Remote Sens. Environ., 73, 337-349, 2000.

Stier, P., Feichter, J., Kinne, S., Kloster, S., Vignati, E., Wilson, J., Ganzeveld, L., Tegen, I., Werner, M., Balkanski, Y., Schulz, M., Boucher, O., Minikin, A., and Petzold, A.: The aerosolclimate model ECHAM5-HAM, Atmos. Chem. Phys., 5, 11251156, 2005,

http://www.atmos-chem-phys.net/5/1125/2005/.

Storelvmo, T., Kristjánsson, J. E., and Lohmann, U.: Aerosol influence on mixed-phase clouds in CAM-Oslo, J. Atmos. Sci., 65, 3214, doi:10.1175/2008JAS2430.1, 2008.

Sundqvist, H., Berge, E., and Kristjánsson, J. E.: Condensation and Cloud Parameterization Studies with a Mesoscale Numerical Weather Prediction Model, Mon. Weather Rev., 117, 1641-1657, 1989.

Textor, C., Schulz, M., Guibert, S., Kinne, S., Balkanski, Y., Bauer, S., Berntsen, T., Berglen, T., Boucher, O., Chin, M., Dentener, F., Diehl, T., Easter, R., Feichter, H., Fillmore, D., Ghan, S., Ginoux, P., Gong, S., Grini, A., Hendricks, J., Horowitz, L., Huang, P., Isaksen, I., Iversen, I., Kloster, S., Koch, D., Kirkevåg, A., Kristjansson, J. E., Krol, M., Lauer, A., Lamarque, J. F., Liu, X., Montanaro, V., Myhre, G., Penner, J., Pitari, G., Reddy, S., Seland, Ø., Stier, P., Takemura, T., and Tie, X.: Analysis and quantification of the diversities of aerosol life cycles within AeroCom, Atmos. Chem. Phys., 6, 1777-1813, 2006,

http://www.atmos-chem-phys.net/6/1777/2006/.
Timmreck, C. and Schulz, M.: Significant dust simulation differences in nudged and climatological operation mode of the AGCM ECHAM, J. Geophys. Res., 109, D13202, doi:10.1029/2003JD004381, 2004.

Tompkins, A. M.: A prognostic parameterization for the subgridscale variability of water vapor and clouds in large-scale models and its use to diagnose cloud cover, J. Atmos. Sci., 59, 1917 1942, 2002.

Tost, H., Jöckel, P., and Lelieveld, J.: Influence of different convection parameterisations in a GCM, Atmos. Chem. Phys., 6, 54755493, 2006, http://www.atmos-chem-phys.net/6/5475/2006/.

Tost, H., Jöckel, P., Kerkweg, A., Pozzer, A., Sander, R., and Lelieveld, J.: Global cloud and precipitation chemistry and wet deposition: tropospheric model simulations with ECHAM5/MESSy1, Atmos. Chem. Phys., 7, 2733-2757, 2007, http://www.atmos-chem-phys.net/7/2733/2007/.

Verheggen, B., Cozic, J., Weingartner, E., Bower, K., Mertes, S., Connolly, P., Gallagher, M., Flynn, M., Choularton, T., and Baltensperger, U.: Aerosol partitioning between the interstitial and the condensed phase in mixed-phase clouds, J. Geophys. Res., 112, D23202, doi:10.1029/2007JD008714, 2007.

Weng, F., Grody, N. C., Ferraro, R., Basist, A., and Forsyth, D.: Cloud liquid water climatology from the Special Sensor Microwave/Imager, J. Clim., 10, 1086-1098, 1997.

Young, K. C.: A Numerical Simulation of Wintertime, Orographic Precipitation: Part I. Description of Model Microphysics and Numerical Techniques, J. Atmos. Sci., 31, 1735-1748, 1974. 